\title{
Expedition 314 Site C0006 $^{1}$
}

\author{
Expedition 314 Scientists $^{2}$
}

\section{Chapter contents}

Background and objectives.......... 1

Operations...................

Data and log quality .............. 3

Log characterization and lithologic

interpretation ............... 4

Physical properties ..............6 6

Structural geology and geomechanics . . . . . 7

Log-seismic correlation . . . . . . . . . . . 9

Discussion and synthesis. . . . . . . . . . 10

References................... 11

Figures.................... 12

Tables......................... 47

${ }^{1}$ Expedition 314 Scientists, 2009. Expedition 314 Site C0006. In Kinoshita, M., Tobin, H., Ashi, J., Kimura, G., Lallemant, S., Screaton, E.J., Curewitz, D., Masago, H., Moe, K.T., and the Expedition 314/315/316 Scientists, Proc. IODP, 314/315/316: Washington, DC (Integrated Ocean Drilling Program Management International, Inc.). doi:10.2204/iodp.proc.314315316.118.2009 ${ }^{2}$ Expedition 314/315/316 Scientists' addresses.

\section{Background and objectives}

Integrated Ocean Drilling Program (IODP) Site C0006 (proposed Site NT1-03) (Figs. F1, F2) is located at the frontal thrust of the Nankai accretionary prism near the trench axis. Drilling targeted the main frontal thrust at an estimated depth of $\sim 700$ meters below seafloor (mbsf), as well as subsidiary faults and deformed sediments in the hanging wall above that zone and a footwall zone of strong reflectors likely caused by coarse turbiditic trench fill sediments. Overall objectives of drilling this site with loggingwhile-drilling (LWD)-measurement-while-drilling (MWD) instruments were to characterize the lithology, deformation, stress state, and physical properties of the hanging wall rocks and frontal thrust fault zone. LWD drilling during Expedition 314 contributed in situ resistivity, gamma ray, and ultrasonic caliper logs, as well as borehole imagery for this characterization. Unfortunately, no neutron porosity or lithodensity logs were obtained because of the inability to run a radioactive source at this site, and the sonic tool failed to record useful data for most of the interval below 274 $m$ LWD depth below seafloor (LSF) because of loss of the MWD turbine power system.

Based on seismic data and submersible dive studies (Ashi et al., 2002), this frontal thrust system was predicted to have placed moderately consolidated clastic rocks over weak and unlithified upper Quaternary trench section clastic sediments. However, at the final location chosen for Site C0006, it is not clear whether the same older section sampled by submersible is in the thrust sheet or if it is exclusively composed of uplifted trench wedge. Detailed analysis of seismic data suggests that substantial footwall protothrust deformation exists a few hundred meters below the main frontal thrust fault at this site location, implying the existence of a deeper décollement and that strain decoupling is not total across this fault. Reflection amplitude of this fault plane is variable near this site, but generally it is a negative polarity reflector. Characterization of physical properties across the frontal thrust zone, as well as the many subsidiary faults imaged in the thrust sheet, were primary objectives of drilling this site; however, the lack of porosity and velocity data has hampered this effort. Nevertheless, resistivity imaging and other data provides extensive documentation of fracture and stress orientation, lithology, and possible fault repetition of strata. 
Pilot Hole C0006A was drilled with MWD-annularpressure-while-drilling (APWD) and gamma ray tool string to total depth (TD) of $885.5 \mathrm{~m}$ LSF, and Hole C0006B was drilled to the same TD with the full LWD tool string but without any radioactive source in the adnVISION tool. Drilling was smooth; however, real-time MWD communication was lost at 274 $\mathrm{m}$ LSF, as well as the power from the MWD turbine. LWD tools recorded data in memory mode on battery power; however, sonic source transducers were negatively affected and sonic data were of very poor to unusable quality from $274 \mathrm{~m}$ LSF to TD $(885.5 \mathrm{~m}$ LSF). Drilling was initially planned to 950 mbsf but was terminated at 885 mbsf. MWD data showed that drilling was penetrating thick sandy sequences and conditions were deteriorating below $\sim 800 \mathrm{~m}$ LSF. Judging that drilling had passed through the main fault reflector position at $<700 \mathrm{~m}$, we decided the objective had been met and the hole was terminated.

\section{Operations}

\section{Hole C0006A}

The summary of operations in Hole C0006A is shown in Table T1. The drill string was spaced out in preparation for drilling, and the Schlumberger MWD and APWD tools were tested in preparation for drilling pilot Hole C0006A (initial target depth $=950 \mathrm{~m}$ LSF; drilled to $885.5 \mathrm{~m} \mathrm{LSF).} \mathrm{The} \mathrm{bottom-hole} \mathrm{assem-}$ bly (BHA) included polycrystalline diamond compact (PDC) bit, a crossover sub, MWD (PowerPulse) and APWD tools, a stabilizer and nine $63 / 4$ inch drill collars, and one jar (see Fig. F1 in the "Expedition 314 methods" chapter; Table T2). Tools were assembled and we started running into hole between 0040 and $2045 \mathrm{~h}$ on 9 November 2007. Because of the high current, all pipe connections were checked while running in. Because water depth was deeper than the remotely operated vehicle's (ROV's) capability $(3000 \mathrm{~m})$, the hole was positioned based on ship position. After spud-in, drilling and MWD logging operations began at $0015 \mathrm{~h}$ on 10 November. Based on the cumulative length of drilling pipe, the seafloor depth was estimated to be $3903.5 \mathrm{~m}$ (3903.5 $\mathrm{m}$ drillers depth below rig floor [DRF]).

A time version of the surface drilling parameters and downhole MWD measurements of equivalent circulating density (ECD), average annular pressure (APRS), and gamma ray values (GR_RAB) is given in Figure F1. The hole was jetted-in to $3954 \mathrm{~m}$ DRF (50.5 m LSF) with a minimal ( $<2 \mathrm{kkgf})$ weight on bit (WOB) and standpipe pressure (SPPA). Surface pump flow was set to $520 \mathrm{gpm}$. After $50.5 \mathrm{~m}$ LSF, bit rotation (CRPM) was progressively increased to 80-100 $\mathrm{rpm}$ to $150 \mathrm{~m}$ LSF and then stabilized at $\sim 120 \mathrm{rpm}$ to
TD (885.5 m LSF). Increase in CRPM was concomitant with increased SPPA and surface pump flow. A first wiper trip was conducted between 4210 and 4060 m DRF (306.5-156.5 m LSF; 1415-1530 h on 10 November) and a second wiper trip was conducted between 4504 and $4364 \mathrm{~m}$ DRF (600.5-460.5 m LSF; 0500-0545 h on 11 November). Drilling progressed smoothly with an average rate of penetration (ROP) of $\sim 30 \mathrm{~m} / \mathrm{h}$. Normal hydrostatic increase with depth was observed on APRS and ECD. Annular temperature (ATMP) also gradually increased to $12^{\circ} \mathrm{C}$ at the bottom of the hole. Total depth of $885.5 \mathrm{~m}$ LSF was reached at $2045 \mathrm{~h}$ on 11 November, after $45 \mathrm{~h}$ of drilling operations. The BHA was then pulled out of the hole and the drill bit cleared the seafloor at 2400 $\mathrm{h}$ on 11 November. The drill bit was recovered on the rig floor at $1015 \mathrm{~h}$ on 12 November.

\section{Hole C0006B}

The summary of operations in Hole C0006B is shown in Table T1. Hole C0006B was spudded at 0045 h on 13 November 2007. The LWD-MWD drilling/logging operations were conducted from the seafloor (3900.0 m DRF) to TD of $4785.5 \mathrm{~m}$ DRF (885.5 m LSF). As water depth exceeded the $3000 \mathrm{~m}$ ROV limitation, the position of the hole was determined by the position of the ship. At the time of spud-in, ship position was $33^{\circ} 01.6350^{\prime} \mathrm{N}$, $136^{\circ} 47.6390^{\prime} \mathrm{E}$.

Operations began with the makeup of the BHA (from 1115 to $2000 \mathrm{~h}$ on 12 November). The BHA included a PDC bit, various subs, LWD tools, one mechanical jar, nine $63 / 4$ inch drilling collars, and an extra crossover sub to connect the BHA to the drill pipes (Table T3). The LWD tools $(6 \% / 4$ inch $[17.15 \mathrm{~cm}]$ collars) included geoVISION, sonicVISION, MWD (PowerPulse), adnVISION (caliper-only mode), and seismicVISION tools (see Fig. F1 in the "Expedition 314 methods" chapter). Seafloor was tagged at $3900 \mathrm{~m}$ DRF (3871.5 meters below sea level) at $0045 \mathrm{~h}$ on 13 November (Table T1).

Hole C0006B was jetted-in with an initial pump rate of $500 \mathrm{gpm}$ to $\sim 40 \mathrm{~m} \mathrm{LSF}$. Real-time communication with the tools was poor because the pump rate was limited in the slipping mode interval to reduce washout. Graphic representation of drilling parameters and the gamma ray log is given in Figures F3 and F4. Real-time communication with the LWD tools was lost at $1800 \mathrm{~h}$ on 13 November (274 m LSF) because the mud pulse telemetry system failed. Drilling progressed smoothly at a constant ROP of $40 \mathrm{~m} / \mathrm{h}$. CRPM progressively increased from $80 \mathrm{rpm}(40 \mathrm{~m}$ LSF) to 100-120 rpm to the end of operation. Pump flow increased to $700 \mathrm{gpm}$, and SPPA was mostly maintained below $15 \mathrm{MPa}$. Major reaming opera- 
tions were conducted during drilling as a result of an observed increase in hole deviation $\left(\sim 5^{\circ}\right.$ at $240 \mathrm{~m}$ LSF). A wiper trip was conducted from 4502 to 4350 $\mathrm{m}$ DRF (602.5-450.5 m LSF) at 0330-0415 h on 14 November. The target depth of $885.5 \mathrm{~m}$ LSF was reached at $1645 \mathrm{~h}$ on 14 November. The hole was killed by circulating heavy mud, and tools were pulled out at $1900 \mathrm{~h}$. After the drill string was above the seafloor, the drilling equipment and derrick were checked before continuing pullout. LWD tools were recovered on the rig floor at $1715 \mathrm{~h}$ on 15 November, and all data successfully downloaded.

\section{Transit to Hole C0001E}

After pulling out of Hole C0006B, the D/V Chikyu moved $\sim 14 \mathrm{nmi}$ to Site C0001 with an average speed of $3.5 \mathrm{kt}$ at $1700 \mathrm{~h}$ on 15 November 2007 and arrived at the location at $2100 \mathrm{~h}$.

\section{Data and log quality Hole C0006A}

\section{Available data}

Hole C0006A was drilled with MWD-APWD tools. All data were sent to the surface through the drilling fluid telemetry system (see Fig. F3 in the "Expedition 314 methods" chapter). At the end of the drilling operation, time and depth information were merged and data was processed following the data flow presented in Figure F3 in the "Expedition 314 methods" chapter. Retrieved data include

1. Surface drilling control parameters: ROP, hook load (HKLD), surface weight on bit (SWOB), SPPA;

2. Downhole drilling parameters: drill bit (collar) rotation (CRPM_RT), PowerPulse turbine rotation speed (TRPM_RT);

3. Annular pressure data: average annular pressure (APRS_MWD) and temperature (ATMP_MWD) and equivalent circulating density (ECD_MWD); and

4. Gamma ray log (GR_RAB) for further depth correlation over interval 0-879 m LSF (3903.5$4782.5 \mathrm{~m} \mathrm{DRF})$.

\section{Depth shift}

For this hole, the mudline (seafloor) was identified from the first break in the gamma ray log (GRM1) found at $3903.5 \mathrm{~m}$ DRF (Fig. F5) while tagging the seafloor without ROV monitoring. GRM1 is particularly noisy at the seafloor interface because the fast ROP (jet-in) in the unconsolidated formation is incompatible with a reliable statistical count of the ra- dioactive elements of the formation and possible flow of mud around the bit. The depth-shifted version of the surface and downhole drilling data and downhole ECD, APRS, and GRM1 is given in Figure F6. To help connect the time and depth version of the data, the time-depth relationship for Hole C0006A is given in Figure F7.

\section{Logging data quality}

Except for the MWD tool GRM1 log, which is directly related to the formation properties (lithology), all other logs are direct surface drilling and downhole measurements. APRS, ATMP, and ECD derived from APRS show an expected increase with depth. As GRM1 has a high depth of investigation, it is considered reliable despite the lack of hole shape (caliper) data. No repeat data were available in this hole; however, this GRM1 log is well correlated with the gamma ray log (GR_RAB) of the geoVISION resistivity tool (GVR) from Hole C0006B. Minor depth discrepancies can be attributed to lateral variations/ heterogeneities between these two holes (Fig. F8).

\section{Hole C0006B}

\section{Available data}

Hole C0006B was drilled with LWD-MWD-APWD tools. As in Hole C0004A, the adnVISION tool was deployed to obtain ultrasonic caliper data. Despite the loss of real-time communication with the LWD tools (1500 h on 13 November 2007; 345.2 m LSF), drilling operations were conducted to TD $(885.5 \mathrm{~m}$ LSF) and memory data were successfully downloaded.

\section{Depth shift}

For Hole C0006B, the mudline (seafloor) was identified from the first break in the gamma ray log (GR) and resistivity logs (RES_RING, RES_BIT, RES_BD, RES_BM, RES_BS) at $3899.5 \mathrm{~m}$ DRF, showing a discrepancy with drillers depth by $0.5 \mathrm{~m}(3900.0 \mathrm{~m}$ DRF) (Fig. F9). Uncertainty in picking the mudline is clearly within $\pm 1 \mathrm{~m}$ because of the washing out of the top few meters of the unconsolidated formation by drilling fluid and the resultant mixing (formation suspension) at the mudline interface, blurring gamma ray and resistivity readings.

For Hole C0006B, the depth-shifted version of the main drilling data and geophysical logs are given in Figures F8 and F10, respectively. Figure F11 presents the time-depth relationship linking the time (Fig. F2) and depth (Figs. F8, F10) version of the data in Hole C0006B. 


\section{Logging data quality}

Figures F8 and F10 show the quality control logs for Hole C0006B LWD data. The target ROP of $30 \mathrm{~m} / \mathrm{h}$ $( \pm 5 \mathrm{~m} / \mathrm{h})$ was generally achieved to TD (see "Hole C0006B" in "Operations"). This ROP was sufficient to record 1 sample every $4 \mathrm{~cm}$ over the majority of the hole. SPPA increased with depth from 10 to 18 $\mathrm{MPa}$, and no noticeable change in APRS and ECD was observed until the loss of the real-time communication with the LWD-APWD tools. Hole deviation quickly reached $5^{\circ}$ (250 m LSF), but memory data show that hole deviation stabilized with depth, remaining close to $5^{\circ}$ at $885.5 \mathrm{~m} \mathrm{LSF}$.

Hole conditions are highly variable with depth. Sonic caliper values from the adnVISION tool that should be 8.5 inches $(21.6 \mathrm{~cm})$ for a perfect in-gauge hole instead show values $>10$ inches $(25.4 \mathrm{~cm})$ for the upper depth interval (0-200 m LSF), the lower depth interval (710-855 m LSF [last caliper reading]), and a few localized (approximately meter scale) washouts. All these depth intervals are characterized by low gamma ray counts suggesting caving in sandrich layers.

Comparison between deep button (RES_BD) and shallow button (RES_BS) resistivity values shows that drilling fluid invasion is concomitant with low gamma ray depth intervals in spite of the short time after bit measurements. Combined with hole conditions and caliper information, these layers can possibly be interpreted as permeable sand-rich layers.

Because of the limited time available before the end of the cruise, sonicVISION data for Hole C0006B were processed postcruise by the Schlumberger Data Consulting Specialist. The depth interval of usable processed data was limited by the failure of real-time communication and powering of the sonic tool (1500 h on 13 November 2007; $345.2 \mathrm{~m} \mathrm{LSF)}$ and the possible damage of the transmitter. At the time realtime communication failed, the sonic tool switched from turbine mode to battery mode. Because of the low downhole temperature $\left(\sim 3^{\circ} \mathrm{C}\right)$, the batteries did not provide enough voltage to the transmitter, therefore limiting the available energy to excite the formation. Possible damage of the transmitter resulting from improper stabilization of the tool and/or severe drilling conditions (stick-slip or shocks) may have also impaired data quality. As a result, only the uppermost $160 \mathrm{~m}$ has been processed by combining the results of wide and leaky-P processing, attempting to select wide results when available. Quality control analysis of sonic data is based on examination of plots showing sonic waveforms and slowness coherence images for common receiver data and common source data. From 36 to $160 \mathrm{~m}$ LSF, sonic data quality is moderate; discontinuous transit times have been picked using mostly wide processed data. Above 36 $\mathrm{m}$ LSF, formation arrival can not be distinguished from mud arrival (Table T4).

Overall quality of the resistivity images used in structural interpretation is very good (Fig. F10; Table T5). The following descriptions of logging units include areas of apparent artifacts probably reflecting hole or tool conditions and not real geology. This assessment was based on the shallow level of investigation of the GVR tool, displayed as a static, not a dynamically renormalized, image.

\section{Log characterization and lithologic interpretation \\ Log characterization and identification of logging units}

Site C0006 logging units were characterized from visual inspection of gamma ray, resistivity, and caliper log responses (Fig. F1). Resistivity images were used to define finer scale characteristics within the units. Four primary logging units were defined based on the variability of log responses (Tables T6, T7).

Logging Unit I (0-197.8 m LSF) is characterized by a gradual increasing trend starting at $52 \mathrm{~m} \mathrm{LSF}$ and variable gamma ray values from 20 to 70 gAPI. This logging unit is also characterized by high-amplitude fluctuation of ring (1-3 $\Omega \mathrm{m})$, shallow $(0.5-2 \Omega \mathrm{m})$, and deep (1-2.5 $\Omega \mathrm{m}$ ) button resistivity values. Ring and deep button resistivity values in this logging unit increase with depth from 0.5 to $2.0 \Omega \mathrm{m}$. Caliper values show high-frequency and high-amplitude oscillation and the baseline of borehole diameter is consistently large (10-11 inches) over this logging unit (Fig. F1).

Logging Unit II (197.8-428.3 m LSF) is characterized by a gradual increasing trend of gamma ray baseline with depth from 60 to 80 gAPI. Four thick intervals of low gamma ray values (<30 gAPI) are observed at 216-223, 238-245, 298-305, and 330-335 m LSF (Fig. F1). Ring and bit resistivity logs exhibit a constant baseline trend between 1.8 and $2.0 \Omega \mathrm{m}$, except for the interval 280-330 m LSF, which exhibits a variable trend from 1.5 to $2.5 \Omega \mathrm{m}$. Ring and bit resistivity logs also exhibit four conductive intervals to $1.0 \Omega \mathrm{m}$ at the same intervals of low gamma ray values. Shallow and deep button resistivity logs show similar trends and four conductive intervals are sharply defined. This logging unit is also characterized by a decreasing trend of borehole diameter from 10 to 9 inches with distinct washouts as much as 14 inches in diameter corresponding to the low gamma ray intervals (Fig. F1). 
Logging Unit III (428.3-711.5 m LSF) is defined as an interval of high-frequency and high-amplitude gamma ray fluctuations. This logging unit is divided into two subunits (Table T6). Logging Subunit IIIA (428.3-545.3 m LSF) is characterized by a gradual increasing trend in gamma ray baseline from 70 to 90 gAPI. Negative meter-scale spikes of gamma ray values to 50 gAPI are common within this subunit. All resistivity logs exhibit a near constant trend around $1.5 \Omega \mathrm{m}$ (Fig. F1).

Logging Subunit IIIB (545.3-711.5 m LSF) is also characterized by high-frequency and high-amplitude gamma ray log fluctuations. Gamma ray values are more variable (30-100 gAPI) than those found in logging Subunit IIIA (40-90 gAPI) and exhibit the highest values (up to 100 gAPI) in Hole C0006B. More than 20 spikes of low gamma ray values to 30 gAPI are observed in this subunit. Resistivity logs exhibit a variable trend between 1.0 and $2.5 \Omega \mathrm{m}$, with increasing trends in resistivity observed over the intervals 594-652 and 656-710 m LSF. Borehole diameter shows nearly constant values (9 inches) at the upper part of this logging subunit and large variation from 9 to 14 inches below $652 \mathrm{~m}$ LSF. The base of logging Unit III is defined by a sharp decrease in gamma ray and resistivity values (Fig. F1).

Logging Unit IV (711.5 m LSF to TD) is characterized by the lowest gamma ray and resistivity values for this hole. The gamma ray log ranges between 20 and 50 gAPI except for the interval of high gamma ray values (up to 80 gAPI) at 712-730 m LSF. Resistivity logs exhibit a slight deceasing trend with depth from 1.0 to $0.5 \Omega \mathrm{m}$. Resistivity logs show high-frequency oscillation over the interval 711.5-762 $\mathrm{m} \mathrm{LSF}$ and decameter-scale cyclic variation over the lower part of this logging unit. Logging Unit IV is also characterized by high values and high-frequency oscillation of borehole diameter fluctuating between 10 and 14 inches (Fig. F1).

Figure F12 illustrates ring resistivity and gamma ray distributions for the logging units and subunits. The gamma ray log exhibits a trend of gradual increase from logging Unit I to Subunit IIIB, with extremely low values for logging Unit IV. Ring resistivity shows a broad range of values in logging Unit I and a gradual decreasing trend from logging Units II to IV. Figure F13 shows a cross-plot of gamma ray values versus ring resistivity. Logging Unit III is characterized by high gamma ray values. Logging Unit IV is characterized by low gamma ray and resistivity values.

\section{Lithologic interpretation}

Log responses in conjunction with resistivity-at-thebit (RAB) images in Hole C0006B show lithologic characteristics and detailed sedimentary/structural features (Figs. F1, F14, F15).

\section{Logging Unit I}

Logging Unit I is characterized by an increasing baseline trend and oscillation of gamma ray and resistivity values. Resistivity logs and RAB images demonstrate clear decameter- to centimeter-scale alternating bedding. The caliper log shows significant washouts in logging Unit I resulting from the unconsolidated state. These log signatures suggest that the lithology of logging Unit I consists of unconsolidated and uncemented interbeds of sand and mud. Based on the interpretation of borehole images, the general trend of the bedding plane is westward dipping, which is obviously different than trends in lower logging units (Fig. F14).

\section{Logging Unit II}

Logging Unit II is characterized by higher values of gamma ray baseline with several prominent, $\sim 5 \mathrm{~m}$ thick layers with low gamma ray values. This $\log$ character is interpreted as mudstone with major, thick sand layers. Fining-upward sequences in these sand layers are clearly seen in the RAB images as a transition from dark (conductive) at the base of the sequence changing gradually to light (more resistive) toward the sequence top. A similar trend is shown on gamma ray and resistivity logs (Fig. F15). The upper and lower pairs of sand layers are presumably stratigraphic repetition. However, these sand layers and the surrounding formations are not correlated with each other in a simple way because of the complexity of faulting (see "Structural geology and geomechanics" and "Log-seismic correlation"). Bedding dip and orientation patterns within this unit show variability (Fig. F14) that is likely the result of disruption of the original bedding caused by complex deformation.

\section{Logging Unit III}

Logging Unit III is characterized by a high gamma ray baseline with frequent thin low gamma ray layers. These log responses are interpreted as alternating beds of mudstone and sand. Thickness and frequency of coarse layers are quite different from those of logging Unit II. The gamma ray log also suggests that the sand/mud ratio in logging Subunit IIIB (sand-dominant facies) is larger than that formed in logging Subunit IIIA (mud-dominant facies) (Fig. F1).

Based on borehole image interpretation, a number of alternating bedding features are recognized but specific textures or sedimentary features are not clearly imaged. A general trend of bedding is northward and 
southward dipping for logging Subunit IIIA and northward to northwestward dipping for logging Subunit IIIB (Fig. F14). Logging Subunit IIIA is relatively homogeneous and conductive. Logging Subunit IIIB is characterized by three decameter-scale resistive (light) intervals changing to conductive (dark) sediments with depth. These trends are consistent with gamma ray trends and are likely related to textural and compositional changes.

\section{Logging Unit IV}

Very low gamma ray values (lowest in Hole C0006B) suggest that the lithology of logging Unit IV is sand dominated. Borehole diameter is as large as that of logging Unit I, possibly caused by an unconsolidated/uncemented state. Based on borehole image interpretation, sedimentary structures and deformation features are not very clear because of the possible massive character of the formation and also washouts. A general trend of the bedding planes is northward dipping throughout the unit. This bedding structure is slightly different from that of logging Unit III (Fig. F14). All log responses suggest that the lithology of logging Unit IV is uncemented massive sand.

Based on the seismic section (see "Log-seismic correlation"), logging Unit IV is correlated to possible underthrust sediments. Although the lithologic contrast demonstrated by the abrupt decrease of gamma ray and resistivity logs is large between logging Units III and IV, deformation structures between the two logging units are poorly identified (see "Structural geology and geomechanics") and the seismic and RAB structural interpretation places the likely main thrust fault $\sim 50 \mathrm{~m}$ higher at $657 \mathrm{~m}$ LSF within logging Subunit IIIB.

\section{Physical properties}

The available data relevant to physical properties include five different sets of resistivity logs (bit; ring; and shallow, medium, and deep button) and sonic $P$ wave velocity. No neutron porosity (TNPH) or density (RHOB) data were recorded.

As at previous sites, additional analyses were conducted to produce porosity estimates derived from resistivity. In the process, the estimation of temperatures and formation factors were carried out.

\section{Resistivity and estimated porosity}

\section{Resistivity logs}

Figure F16 shows ring and bit resistivity measurements side by side and smoothed logs of shallow, medium, and deep button resistivity. A moving aver- age using a 21-point ( $\sim 3 \mathrm{~m}$ interval) window was used to smooth the resistivity values. Superposition of deep, medium, and shallow button resistivity measurements shows very good agreement between medium and deep button resistivities. Shallow button resistivity is significantly lower than the two other button resistivities in logging Units I and IV (Figs. F16, F17).

Based on bit resistivity, logging Unit I resistivity values generally increase from 1.1 to $2.0 \Omega \mathrm{m}$ and show an important excursion to higher resistivity values from 50 to $100 \mathrm{~m}$ LSF that includes a peak of resistivity of $2.6 \Omega \mathrm{m}$ at $85 \mathrm{~m}$ LSF. The trend of resistivity becomes fairly constant in logging Unit II where it varies slightly around $1.9 \Omega \mathrm{m}$. Four excursions to low resistivity value are noticeable in this unit.

At the top of logging Subunit IIIA (from 429 to 460 $\mathrm{m} \mathrm{LSF}$ ), the trend is a decreasing one from 1.8 to 1.5 $\Omega \mathrm{m}$ and increases again to $1.7 \Omega \mathrm{m}$ at $530 \mathrm{~m}$ LSF. The bottom of this subunit is marked by a sharp minimum of resistivity at $1.3 \Omega \mathrm{m}$. The underlying logging subunit (IIIB) is characterized by alternating zones of higher and lower resistivity values. From 545 to $590 \mathrm{~m}$ LSF, resistivity values fluctuate around $1.7 \Omega \mathrm{m}$ with a minimum in resistivity $(1.2 \Omega \mathrm{m})$ at $560 \mathrm{~m}$ LSF. This zone ends on a decreasing step of resistivity (from 1.8 to $1.4 \Omega \mathrm{m}$ ) and is followed by a zone of constant resistivity values $(1.4 \Omega \mathrm{m})$ from 590 to $615 \mathrm{~m} \mathrm{LSF}$. Below this zone, the trend of resistivity increases again to $2.1 \Omega \mathrm{m}$ at $640 \mathrm{~m} \mathrm{LSF}$, where a second decreasing step is observed (from 2.1 to $1.4 \Omega \mathrm{m}$ ). This decreasing step is followed by a decreasing trend of resistivity (from $1.4 \Omega \mathrm{m}$ at $655 \mathrm{~m}$ LSF to 1.2 $\Omega \mathrm{m}$ at $690 \mathrm{~m}$ LSF) and an increasing trend (from 1.2 $\Omega \mathrm{m}$ at $690 \mathrm{~m}$ LSF to $1.7 \Omega \mathrm{m}$ at $710 \mathrm{~m} \mathrm{LSF).} \mathrm{The}$ boundary between logging Units III and IV is marked by a decreasing step of resistivity from 1.7 to $1.2 \Omega \mathrm{m}$.

The trend of resistivity stays fairly constant $(1.2 \Omega \mathrm{m})$ in the uppermost $30 \mathrm{~m}$ of logging Unit IV. At $740 \mathrm{~m}$ LSF another decreasing step of resistivity is observed (from 1.2 to $0.9 \Omega \mathrm{m}$ ), followed by a nearly constant trend of resistivity $(0.9 \Omega \mathrm{m})$. At $840 \mathrm{~m}$ LSF a final increasing step of resistivity is observed from 0.8 to 1.2 $\Omega \mathrm{m}$ followed by a decreasing trend of resistivity reaching $0.75 \Omega \mathrm{m}$ at the bottom of the hole.

\section{Estimation of temperature profile}

The downhole temperature profile was estimated from a regional surface heat flow of $80 \mathrm{~mW} / \mathrm{m}^{2}$ (Kinoshita et al., 2003) and $2^{\circ} \mathrm{C}$ surface temperature. Thermal conductivity $(k)$ was estimated from Ocean Drilling Program Leg 131 Site 808 data as $k=1+(z /$ 800) for $z<400 \mathrm{~m}$ and $k=1.5+(z-400) / 2000$ for $z>$ $400 \mathrm{~m}$. The estimated temperature is $52^{\circ} \mathrm{C}$ at $886 \mathrm{~m}$ LSF. 


\section{Estimation of porosity from resistivity}

Bit and ring formation factors have been calculated from resistivity logs and temperature-corrected seawater electrical resistivity. They were converted to porosity using Archie's law. In the absence of neutron porosity data to calibrate Archie's law parameters, the parameter values $a=1$ and $m=2.4$ were used. The values are the same as those at previously drilled Expedition 314 sites where these values were calibrated from comparison with log porosity data (neutron and density porosity). However, sand content at Site C0006, apparently much greater than that found at other sites, means that porosity and density estimates may be strongly affected by lithology, which is not accounted for in these calculations.

In logging Unit I, bit resistivity-derived porosity decreases from $85 \%$ at $0 \mathrm{~m} \mathrm{LSF}$ to $51 \%$ at $50 \mathrm{~m} \mathrm{LSF}$ (Fig. F18) and $41 \%$ at $86 \mathrm{~m}$ LSF. Resistivity-derived porosity then increases to $49 \%$ at $116 \mathrm{~m}$ LSF and decreases back to $40 \%$ at $197.8 \mathrm{~m} \mathrm{LSF}$ at the boundary between logging Units I and II. In Unit II, resistivity-derived porosity decreases slowly to $38 \%$ at $428 \mathrm{~m} \mathrm{LSF}$, the transition with Unit III. In the uppermost $34 \mathrm{~m}$ of Unit III, resistivity-derived porosity increases to $41 \%$ at $462 \mathrm{~m} \mathrm{LSF}$ and then decreases to $36 \%$ at $590 \mathrm{~m}$ LSF. At the base of Unit III, resistivity-derived porosity is $36 \%$ and jumps to $41 \%$ over $6 \mathrm{~m}$ at the transition with Unit IV. In Unit IV, resistivity-derived porosity begins by increasing to $48 \%$ at $762 \mathrm{~m} \mathrm{LSF}$. Resistivity-derived porosity then fluctuates around an average value of $46 \%$. At $850 \mathrm{~m}$ LSF resistivityderived porosity decreases to a low value of $39 \%$ before increasing back to $47 \%$ at $884 \mathrm{~m} \mathrm{LSF}$ at the base of the hole. Again, caution is required in interpreting these values, as Unit IV is interpreted as being a much sandier lithology than the basis of calibration (see "Log characterization and lithologic interpretation").

\section{Estimation of density}

Because of the absence of bulk density measurements, we made an estimation of bulk density from resistivity-derived porosity (Fig. F18). Resistivityderived porosity was converted to density using standard methods (see "Physical properties" in the "Expedition 314 methods" chapter).

\section{$P$-wave velocity}

Because of a malfunction of the sonic tool at Site C0006, $P$-wave velocity data were measured only to $160 \mathrm{~m}$ LSF, which corresponds to sediments in most of logging Unit I (Fig. F19). In the uppermost $40 \mathrm{~m}$, the measured $P$-wave velocity is indistinguishable from the mud arrival ( $1500 \mathrm{~m} / \mathrm{s})$. At $\sim 40 \mathrm{~m}$ LSF, ve- locity jumps to $\sim 1750 \mathrm{~m} / \mathrm{s}$. Below this level, velocity appears to be nearly constant or slightly increasing. At the base of measurements (160 m LSF), velocity is measured at $\sim 1860 \mathrm{~m} / \mathrm{s}$. Some velocity peaks are noted at 70, 94, 101, and 130-140 m LSF, which may be interpreted as clay-rich intervals where gamma ray values are relatively high (see "Log characterization and lithologic interpretation").

Velocity and resistivity are generally in good agreement; high velocity zones correspond to high resistivity zones. This is clearly seen in the cross-plot between velocity and bit resistivity, in which their relationship is approximately linear (Fig. F20). The only exception is high-resistivity data $(>2 \mathrm{~m})$ in the interval between 80 and $90 \mathrm{~m}$ LSF. In this lowgamma ray sandy zone, velocities are low $(\sim 1700 \mathrm{~m} / \mathrm{s})$.

\section{Structural geology and geomechanics}

Very good quality borehole resistivity images provide information on orientation of bedding, fractures, and breakouts at Site C0006 (Fig. F21). In addition, the overall stratigraphic sequence and seismic reflection images allow interpretation of the structural geology.

\section{Observations}

\section{Bedding}

Bedding dips are shallow to moderate with most dips $<45^{\circ}$. Bedding orientation is partitioned downhole with mostly westward dips above $198 \mathrm{~m}$ LSF (logging Unit I) (Figs. F21, F22). Dips below 428 m LSF (logging Units III and IV) are northwestward. Dips between 198 and $428 \mathrm{~m} \mathrm{LSF}$ (logging Unit II) are diverse and do not meaningfully cluster.

\section{Natural fractures and fractured zones}

Fracture analysis from borehole images is primarily based on orientation, dip, and resistive character relative to surrounding sediments. Most fractures are conductive (Figs. F21, F23) with more resistive fractures identified within logging Units II and III. Fracture dips range from $\sim 30^{\circ}$ to $80^{\circ}$ with no clear pattern in dip magnitude variation between logging units.

Overall orientation of fractures within the borehole is scattered. However, when fractures are divided into the four logging units (Fig. F24), distinct trends can be identified. Logging Units I and II are characterized by fractures predominantly striking northwest-southeast. In contrast, logging Units III and IV are characterized by fractures striking northeastsouthwest. 
In logging Unit I a second set of fractures strike northeast-southwest and dip southeastward. For the major fracture trend (northwest-southeast), fractures evenly dip toward the northeast and southwest. In logging Unit II (predominant northwest-southeast trend) many fractures dip toward the northeast. Fractures in logging Unit III are moderately scattered but with the largest subset dipping toward the northwest (trending northeast-southwest). Finally, fractures are more difficult to identify in logging Unit IV because of the high background conductivity of the borehole. For those fractures that have been identified, the predominant trend is closer to west-southwesteast-northeast and the majority dip toward the north-northwest.

\section{Borehole breakouts}

Borehole breakouts occur from 188 to 729 m LSF but are not readily discernible at greater depths. The mean azimuth of the breakouts is $060^{\circ}$ (Fig. F25A) with some variation but no clear trend with depth (Fig. F25B). The overall mean width of breakouts is $44^{\circ}$ (Fig. F25C). The weighted average of breakout widths decreases downhole, although there is considerable scatter locally to larger widths (Fig. F25D).

\section{Interpretations}

\section{Bedding}

Overall the bedding dip orientations below $428 \mathrm{~m}$ LSF are consistent with north-northwestward directed shortening, which could be caused by the plate convergence. The generally westward dips above $198 \mathrm{~m}$ LSF may reflect a rotation by gravitational slumping caused by a locally steep southwestward component of the topographic slope (Fig. F26). The westward dips above $198 \mathrm{~m}$ LSF could therefore be explained by a northwestward tilt caused by plate convergence with a superimposed southwestward tilt caused by gravitational slumping.

\section{Correlations of conductive fractures with seismically inferred faults}

Although the borehole images do not show clear-cut fracture zones, some conductive fractures may correlate with seismically inferred faults (Fig. F27). For example, in the zone of subsidiary thrust faulting between 200 and $600 \mathrm{~m}$ LSF conductive fractures occur at 360 and $381 \mathrm{~m}$ LSF that are close to the seismically inferred thrust faults. Moreover, a well-developed conductive fracture zone and a fold occurs at $657 \mathrm{~m}$ LSF (Fig. F23) that may correlate with the main frontal thrust below the zone of subsidiary thrusts. Fractures recognized in the borehole images are generally moderately dipping. There may be others of shallow dip that are indistinguishable from bedding and not identified in our analysis. Notably, the fractures discussed here are not well-developed major deformation zones and their correlations with seismic data are tentative and will be tested by coring.

Logging Unit II includes four highly conductive intervals, probably sand beds. The sharp bases of the beds occur at 223, 244.5, 305, and $335 \mathrm{~m}$ LSF (Fig. F1). The seismic depth section (Fig. F27) shows thrust faults between some of these distinctive beds, suggesting displacement and potential repetition. The borehole images do not show obvious major faults or fracture zones separating these beds. However, as mentioned above, our detection of faults and fractures is biased toward those that are more steeply dipping. The hypothesis that these beds are repeated by thrust faulting can be tested by coring and associated dating.

\section{Fractures}

Although fracture orientations are not strongly clustered, a significant shift occurs below $428 \mathrm{~m}$ LSF. Northwest-southeast striking fractures in logging Units I and II (above $428 \mathrm{~m} \mathrm{LSF}$ ) may be related to the southwest component of slope. That is, the southwest and northeast dips could represent a conjugate fracture system related to gravitational failure along the southwest facing slope. Overall fracture orientation below $428 \mathrm{~m}$ LSF is consistent with northwestward directed shortening and breakout orientations. Both fractures and bedding show orientations at shallow depths that may reflect gravitational processes, whereas deeper fractures and bedding can be better explained by tectonic processes.

In comparison to IODP Sites C0001 and C0004 upslope, there are no distinct highly deformed zones or concentrations of fractures at Site C0006. Deformation at this frontal thrust location appears to be in a less evolved state than sites farther landward in the accretionary prism. Although Site C0006 shows some discrete conductive fractures that arguably correlate with seismically inferred faults, localization and intensity of structural features are significantly less than those found at Site 808 (a similar frontal thrust location) along the Muroto transect of the Nankai Trough (Ienaga et al., 2006; McNeill et al., 2004). This apparent greater intensity of strain at Site 808 relative to Site C0006 may reflect the thinner incoming sedimentary sequence at Site 808 (about half as thick as those formed at Site C0006) with approximately equivalent convergence rate or may potentially reflect different sediment properties and consequently differing style of deformation. 


\section{Borehole breakouts}

The decrease in mean breakout width with depth may indicate increasing rock strength with depth, although considerable scatter toward higher values suggests weak intervals persist. The lack of obvious breakouts below $729 \mathrm{~m}$ LSF occurs just below the transition to logging Unit IV, which is interpreted as dominated by sand. Excessive washouts in this interval may obscure the breakouts, but some sandy units uphole also show large caliper readings and do produce distinguishable breakouts. The breakouts indicate an $S_{\text {H max }}$ orientation of $330^{\circ}$, which is generally consistent with that observed at Sites C0001 and C0004 but slightly divergent from the $S_{\mathrm{Hmax}}$ expected from the convergence direction of the Philippine Sea plate and Japan (Fig. F26).

\section{Log-seismic correlation Seismic reflection interpretation}

The upper part of Hole C0006A penetrated a section of accreted trench strata at the prism toe. The section is cut by several northwest-dipping thrust faults that offset the sedimentary reflections. At least two reflections, shown in yellow and blue on Figure F27, are repeated at the borehole by thrust faults. The deepest fault, which continues to the southeast, is inferred to be the main frontal thrust between the overriding thrust sheet and the underthrusting trench sediment section. The complex pattern of reflections below the main frontal thrust is believed to represent channels within the upper part of the trench sediment section that are being overridden by the thrust sheet above.

\section{Check shot survey data}

Check shot data were acquired at 44 depths in Hole C0006B. Two stations were unusable because of excessive noise levels and two others were above the seafloor, but the remaining 40 stations yielded excellent quality waveforms (Fig. F28). These data sample depths from the seafloor to $863.09 \mathrm{~m} \mathrm{LSF}$. Approximately 15 air gun array shots were fired at each station during LWD drilling, and eight shots were fired at each station during the pipe trip out of the hole. We note that before tripping out of the hole, only one $9.5 \mathrm{~m}$ joint was removed, rather than the planned two, so a nonuniform station spacing resulted.

Noisy traces and traces with poor first arrival waveforms were deleted. The remaining traces were filtered (trapezoidal, zero phase, and 30-40-150-200 Hz band-pass) and stacked to produce the traces shown in Figure F28. The first arrival wavelet is unambiguous on all traces.

The first arrival time was picked manually to yield a correlation between seismic traveltime and depth (Table T8). Raw interval and average velocities were determined for each interval. We applied a damped least-squares inversion to the observed depth-time data (Lizarralde and Swift, 1999). This inversion determines a smooth velocity-depth curve by varying the arrival times by amounts that are within their uncertainty. We estimated the uncertainty of the arrivals to be $\sim 0.3 \mathrm{~ms}$. We used an inversion damping coefficient of 0.5 because it produced a $\chi^{2}$ value consistent with the optimal balance between overfitting and underfitting the data. The improvement in estimated interval velocities, indicated by the smoothness of the curve and the general downward increase of velocity (Fig. F29), is dramatic. The accompanying changes in arrival times are very small. We used smoothed arrival picks and tool depths as the check shot curve, which we then used for correcting the seismic depth section through the drill site (Fig. F27).

We were not able to construct a meaningful vertical seismic profile (VSP) using these data. We tried a number of filtering and gain combinations but could not identify coherent upward-traveling reflections. We attribute this to noise from the banging of the drill pipe in the current and other sources of downhole noise.

\section{Overall log unit correlation}

To visualize the correlation of log and seismic reflection data at this site, we present a series of figures (Figs. F28, F29, F30, F31, F32, F33, F34) in which we have superimposed logs over a portion of the check shot-corrected prestack depth-migrated seismic reflection profile. Logging units do not correlate well with the seismic reflection data, probably because the section is strongly faulted (Fig. F30). Several features in the LWD logs do, however, correlate with features in the seismic data. For example, the sandy layers (low gamma ray values and low resistivity) at 220, 240, 300, and 335 m LSF correlate with strong reflections and appear to be parts of the same unit that have been repeated as a result of thrusting (Figs. F27, F31, F32, F33). Several seismically defined thrust faults also correlate with features in the resistivity images, such as the conductive fractures at 360 and $381 \mathrm{~m}$ LSF (see "Structural geology and geomechanics"). The main frontal thrust correlates with a dramatic increase in hole size (Fig. F34) and may correlate with a fracture at $657 \mathrm{~m} \mathrm{LSF} \mathrm{(Fig.} \mathrm{F29).}$ 


\section{Discussion and synthesis}

Site C0006 is located at the toe of the entire accretionary prism near the trench floor, and drilling targeted the main frontal thrust at $\sim 700 \mathrm{mbsf}$, as well as uplifted and complexly faulted sediments in the thrust sheet and less deformed trench fill in the footwall of the main frontal thrust. Hole C0006B was drilled with a full LWD tool string except for nuclear tools to TD (885.5 m LSF). Because the water depth was beyond the ROV limit of $3000 \mathrm{~m}$, holes were drilled without ROV monitoring. Drilling was smooth; however, the loss of MWD communication effectively eliminated sonic data acquisition from 274 to $885.5 \mathrm{~m} \mathrm{LSF}$. Drilling at this site set the record for the deepest water depth $(3871.5 \mathrm{~m})$ drilled by the Chikyu.

Four logging units were defined based on differing trends and the character of LWD log responses. Logging Unit I (0-197.8 m LSF) is interpreted as sandy and muddy deposits. Logging Unit II (197.8-428.3 m LSF) is interpreted as mud with occasional thick $(\sim 5$ $\mathrm{m})$ sand layers. Logging Unit III (428.3-711.5 m LSF) is defined as alternating beds of mud and sand and is divided into two subunits. The base of logging Unit II is interpreted as a possible fault zone as well as a distinct lithologic boundary. Logging Unit III (711.5 $m$ LSF to TD) is characterized by low gamma ray values and low resistivity and is interpreted as sandy deposits. Logging Unit IV has the lowest gamma ray values and is interpreted as underthrust, coarse, trench-fill sediments.

\section{Faults within the thrust sheet}

Within logging Unit II at Site C0006, sediment layers are cut by several northwest-dipping thrust faults that offset sedimentary reflections. The resistivity image and other properties at this site, however, show only moderate fracturing with no obvious major faults or fracture zones separating these layers.

Logging Unit II includes four highly conductive intervals, probably $\sim 5 \mathrm{~m}$ thick sand beds. The sharp bases of these beds occur at 223, 244.5, 305, and 335 $\mathrm{m}$ LSF. The seismic depth section (Figs. F27, F30) shows faults between some of these distinctive beds, suggesting thrust displacement and potential repetition. The hypothesis that these beds are repeated by thrust faulting was tested by coring and associated dating during Expedition 316.

\section{Main frontal thrust}

The gamma ray baseline gradually increases with depth throughout logging Units I-III. Within logging Unit IV below $711 \mathrm{~m}$ LSF, the gamma ray value suddenly decreases from $\sim 90$ gAPI at the bottom of
Unit III to 20-50 gAPI in Unit IV. Lower resistivity and larger borehole diameter accompany this low gamma ray trend, indicating that Unit IV is dominated by unconsolidated sand. From lithologic interpretation, we interpret that Unit IV corresponds to the underthrust trench-fill sediments and that the Unit III/IV boundary corresponds to the main frontal thrust.

Alternatively, from structural interpretation of resistivity images, a well-developed conductive fracture zone ( 1 $\mathrm{m}$ thick) and a fold occur at $657 \mathrm{~m}$ LSF (Fig. F23) within logging Unit III, across which the resistivity abruptly decreases following a thick zone of high resistivity. Although no significant change in gamma ray response is present, this fracture zone and change in the resistivity log may correlate with the main frontal thrust below the zone of subsidiary thrusts, although we acknowledge that this feature does not appear as a major fault zone. The complex pattern of seismic reflections below the main frontal thrust may represent channels within the upper part of the trench sediment section that are being overridden by the thrust sheet.

\section{Deformation and stress orientation near the toe of accretionary prism}

Analysis of both bedding and fracture orientation at Site C0006 documents how the formation has been deformed under the local or regional stress field.

Within logging Unit I, bedding planes are west-dipping. In logging Unit II, bedding dip and orientation patterns show variability. Bedding is predominantly north-dipping in logging Units III and IV.

Fractures at Site C0006 are notable in that they are not as clustered into zones as those found at Sites C0001 or C0004, and no major deformed zones are identified, suggesting generally weaker deformation at Site C0006. Fractures mostly strike northwestsoutheast in logging Units I and II $(<428 \mathrm{~m} \mathrm{LSF})$, whereas fractures in Units III and IV (429-853 m LSF) strike northeast-southwest.

Overall, both fracture and bedding orientations at depths $>429 \mathrm{~m}$ LSF are consistent with northwesterly directed shortening resulting from plate convergence. Fracture and bedding orientations at these depths are also consistent with breakout orientations. At shallower depths, fracture and bedding orientations deviate from this general orientation and probably result from combined regional tectonic and local effects (such as gravitational processes).

Borehole breakouts occur from 188 to 729 m LSF but are not readily discernible at greater depths. Taken as a whole, breakouts are more weakly developed at Site C0006 than at any of the upslope sites. Breakouts 
show mean $S_{\mathrm{Hmax}}$ orientation of $330^{\circ}$ with little variation downhole, consistent with that observed at Sites C0001 and C0004 but slightly divergent from the $S_{\mathrm{H} \max }$ expected from the convergence direction between the Philippine Sea plate and Japan. The lack of obvious breakouts below 729 m LSF occurs just below the transition to logging Unit IV, which is dominated by sand. Excessive washouts in this interval may have obscured the breakout signal.

In logging Unit III (429- $711 \mathrm{~m}$ LSF), fracture and bedding orientation is in agreement with the $S_{\mathrm{H} \max }$ direction calculated from breakouts. Within logging Units I and II, however, fracture and bedding orientations are not what is predicted by $S_{\mathrm{H} \max }$ orientation. The reason for this is unclear, but detailed postcruise research (integrating log, core, and seismic data) may help to resolve this issue.

\section{References}

Ashi, J., Kuramoto, S., Morita, S., Tsunogai, U., Goto, S., Kojima, S., Okamoto, T., Ishimura, T., Ijiri, A., Toki, T., Kudo, S., Asai, S., and Utsumi, M., 2002. Structure and cold seep of the Nankai accretionary prism off Kumano-outline of the off Kumano survey during YK01-04 Leg 2 cruise. JAMSTEC J. Deep Sea Res., 20:1-8.

Heki, K., 2007. Secular, transient and seasonal crustal movements in Japan from a dense GPS array: implication for plate dynamics in convergent boundaries. In Dixon, T., and Moore, C. (Eds.), The Seismogenic Zone of Subduction Thrust Faults: New York (Columbia Univ. Press), 512-539.
Ienaga, M., McNeill, L.C., Mikada, H., Saito, S., Goldberg, D., and Moore, J.C., 2006. Borehole image analysis of the Nankai accretionary wedge, ODP Leg 196: structural and stress studies. Tectonophysics, 426(1-2):207-220. doi:10.1016/j.tecto.2006.02.018

Kinoshita, M., Goto, S., Hamamoto, H., and Yamano, M., 2003. Heat flow distribution and thermal regime across the Nankai accretionary complex. Eos, Trans. Am. Geophys. Union, 84(46)(Suppl.):T42C-06. (Abstract)

Lizarralde, D., and Swift, S., 1999. Smooth inversion of VSP traveltime data. Geophysics, 64(3):659-661. doi:10.1190/1.1444574

McNeill, L.C., Ienaga, M., Tobin, H., Saito, S., Goldberg, D., Moore, J.C., and Mikada, H., 2004. Deformation and in situ stress in the Nankai accretionary prism from resistivity-at-bit images, ODP Leg 196. Geophys. Res. Lett., 31(2):L02602. doi:10.1029/2003GL018799

Miyazaki, S., and Heki, K., 2001. Crustal velocity field of southwest Japan: subduction and arc-arc collision. J. Geophys. Res., 106(B3):4305-4326. doi:10.1029/ 2000JB900312

Moore, G.F., Bangs, N.L., Taira, A., Kuramoto, S., Pangborn, E., and Tobin, H.J., 2007. Three-dimensional splay fault geometry and implications for tsunami generation. Science, 318(5853):1128-1131. doi:10.1126/science. 1147195

Seno, T., Stein, S., and Gripp, A.E., 1993. A model for the motion of the Philippine Sea plate consistent with NUVEL-1 and geological data. J. Geophys. Res., 98(B10):17941-17948. doi:10.1029/93JB00782

Publication:11 March 2009

MS 314315316-118 
Figure F1. Summary log diagram, Site C0006. LSF = LWD depth below seafloor. VE = vertical exaggeration. Black tadpoles = bedding, red tadpoles = fracture, tadpole line = dip direction of plane

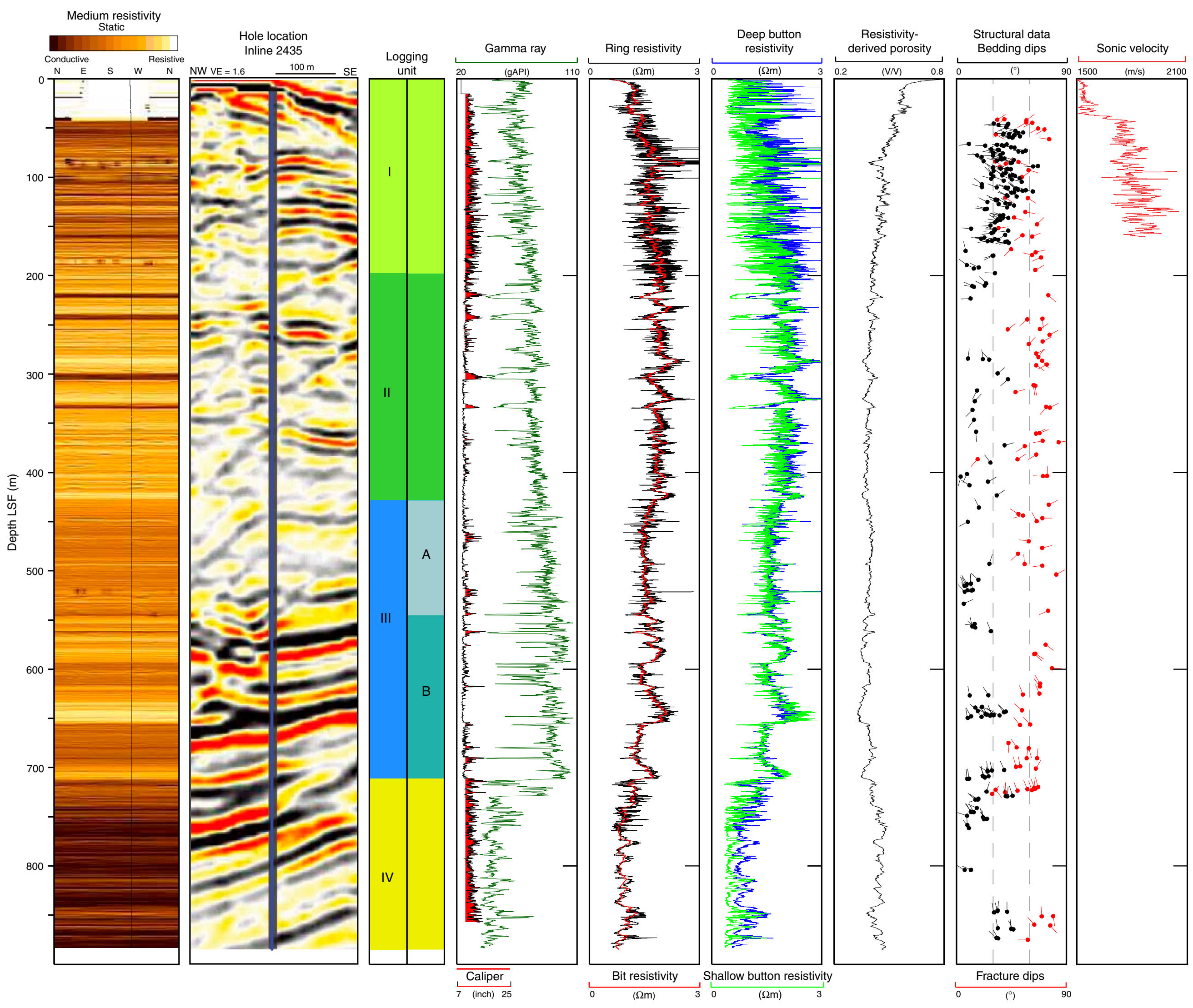




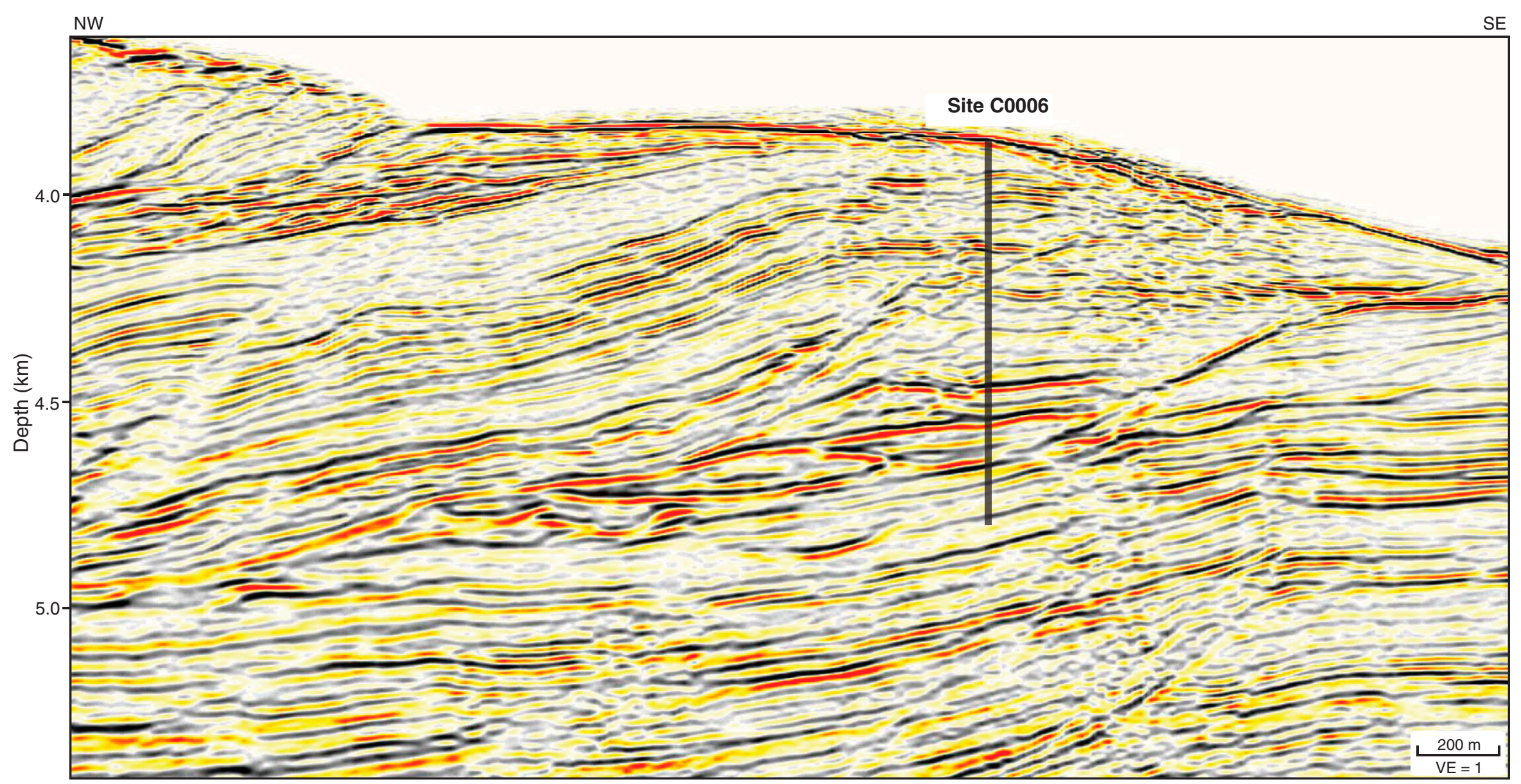


Figure F3. Drilling parameters and gamma ray log plotted vs. time for MWD-APWD operations, Hole C0006A. GR_RAB = MWD tool real-time gamma ray log, ATMP = annular temperature, ECD = equivalent circulating density, $\mathrm{APRS}=$ average annular pressure, $\mathrm{TRPM}=\mathrm{MWD}$ turbine rotation speed $(\mathrm{off}=<1500$ or $>4500 \mathrm{rpm}$, on $=$ 1500-4500 rpm), CRPM = collar rotation, $\mathrm{SWOB}=$ surface weight on bit, HKLD = hook load, SPPA = standpipe pressure, $\mathrm{ROP}=$ rate of penetration, ROP_5ft $=5 \mathrm{ft}$ averaged ROP, LSF $=$ LWD depth below seafloor, DRF $=$ drillers depth below rig floor.

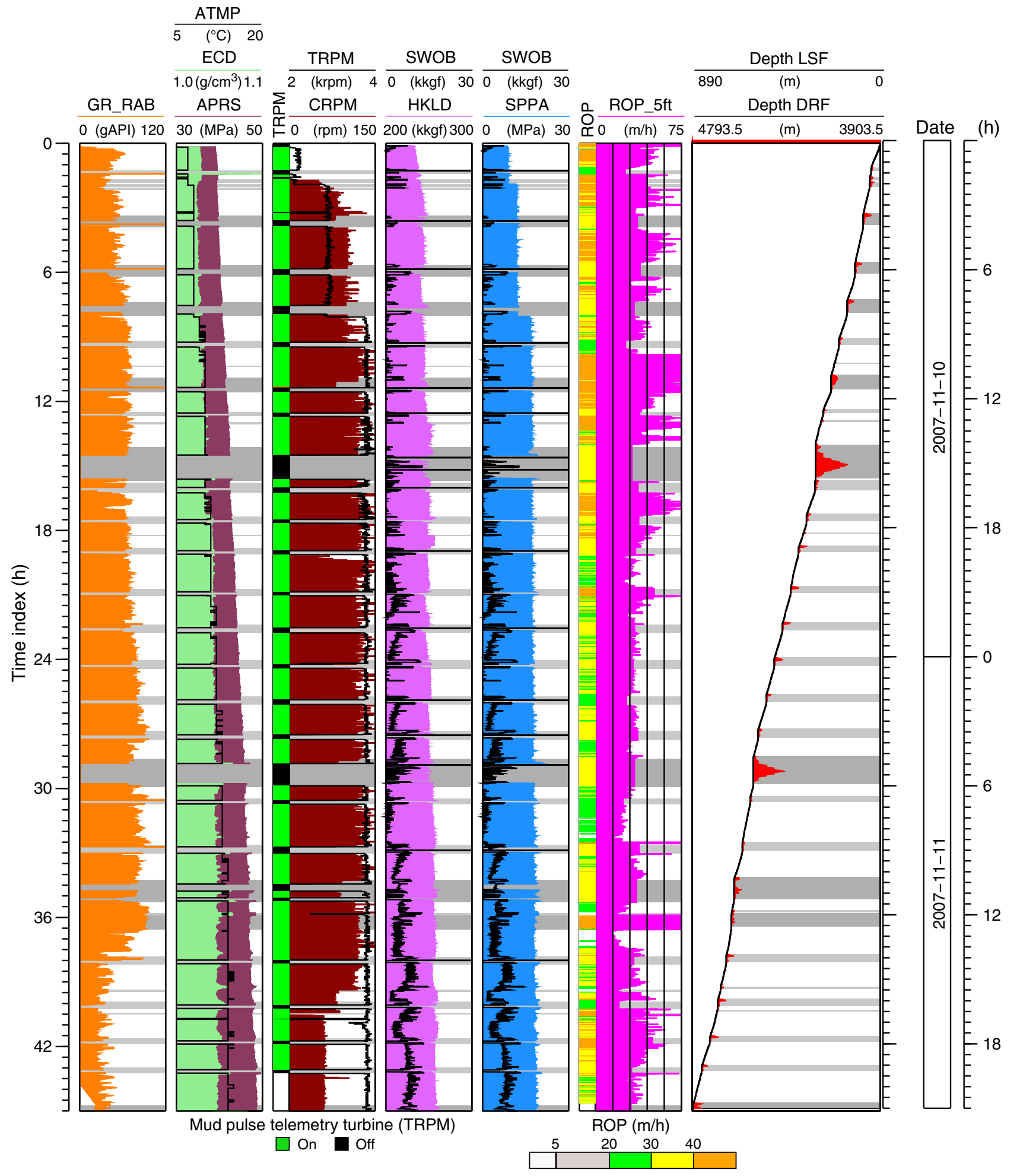


Figure F4. Drilling parameters and gamma ray log plotted vs. time for LWD-MWD-APWD operations, Hole C0006B. GR_RAB = MWD tool real-time gamma ray log, ATMP = annular temperature, ECD = equivalent circulating density, APRS = average annular pressure, TRPM $=$ MWD turbine rotation speed (off $=<1500$ or $>4500$ $\mathrm{rpm}$, on $=1500-4500 \mathrm{rpm}), \mathrm{CRPM}=$ collar rotation, $\mathrm{SWOB}=$ surface weight on bit, HKLD = hook load, SPPA = standpipe pressure, ROP $=$ rate of penetration, ROP_5ft $=5 \mathrm{ft}$ averaged ROP, LSF $=$ LWD depth below seafloor, $\mathrm{DRF}=$ drillers depth below rig floor. Note loss of real-time communication with LWD tools at $1800 \mathrm{~h}$ on 13 November 2007 (345.2 m LSF).

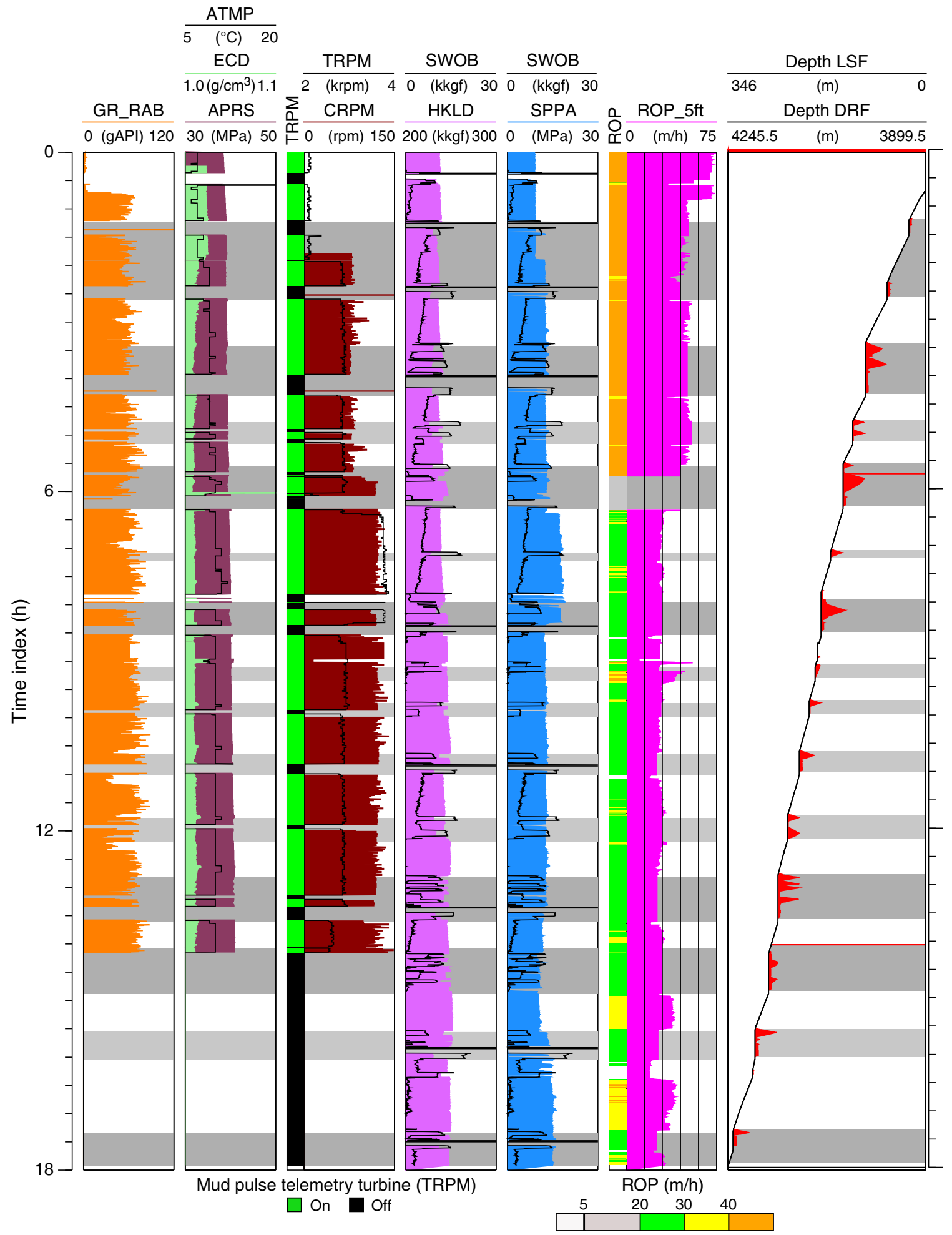


Figure F5. Mudline identification using MWD tool real-time gamma ray log, Hole C0006A. DRF = drillers depth below rig floor, LSF = LWD depth below seafloor.

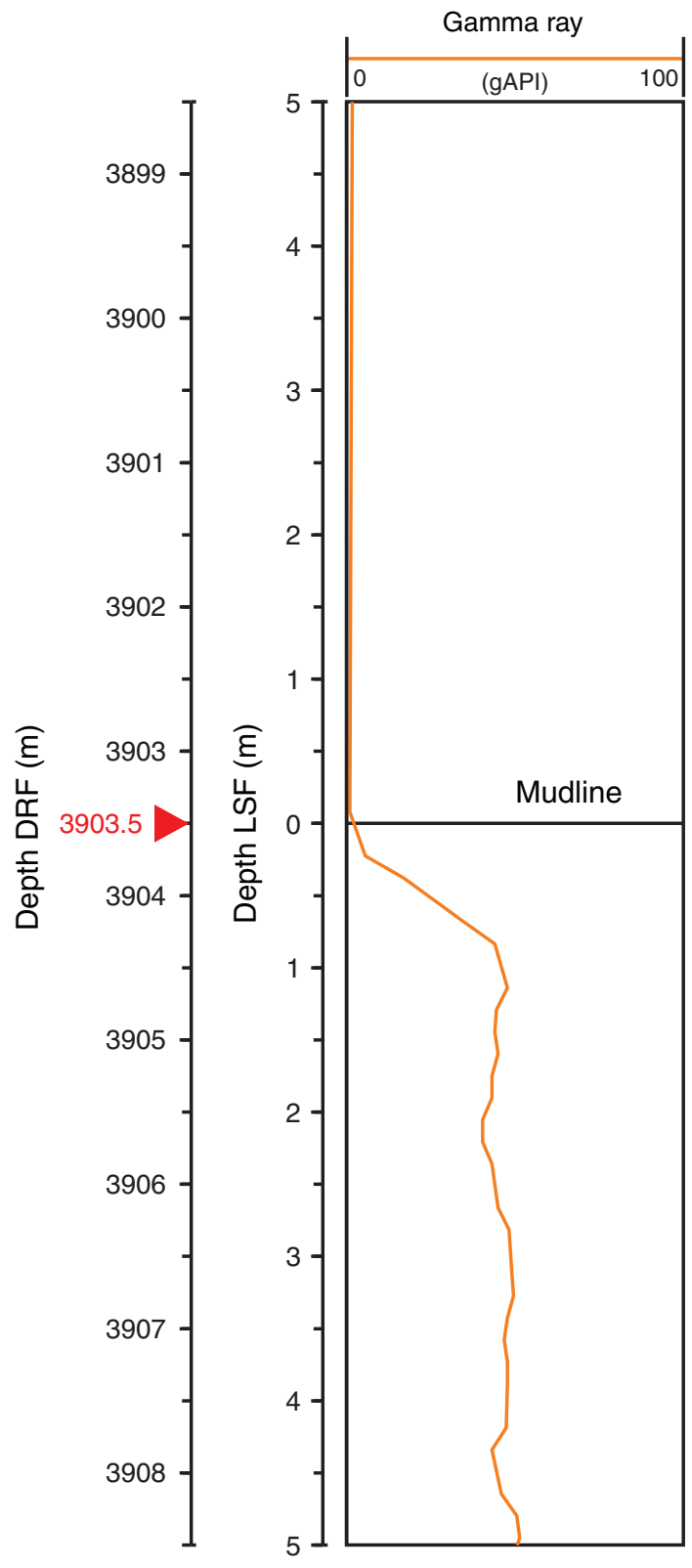


Figure F6. Control logs, Hole C0006A. LSF $=$ LWD depth below seafloor, ROP $=$ rate of penetration, $\mathrm{SWOB}=$ surface weight on bit, ROP_5ft $=5 \mathrm{ft}$ averaged ROP, HKLD = hook load, SPPA = standpipe pressure, ECD = equivalent circulating density, APRS = average annular pressure, GRM1 = gamma ray (MWD).

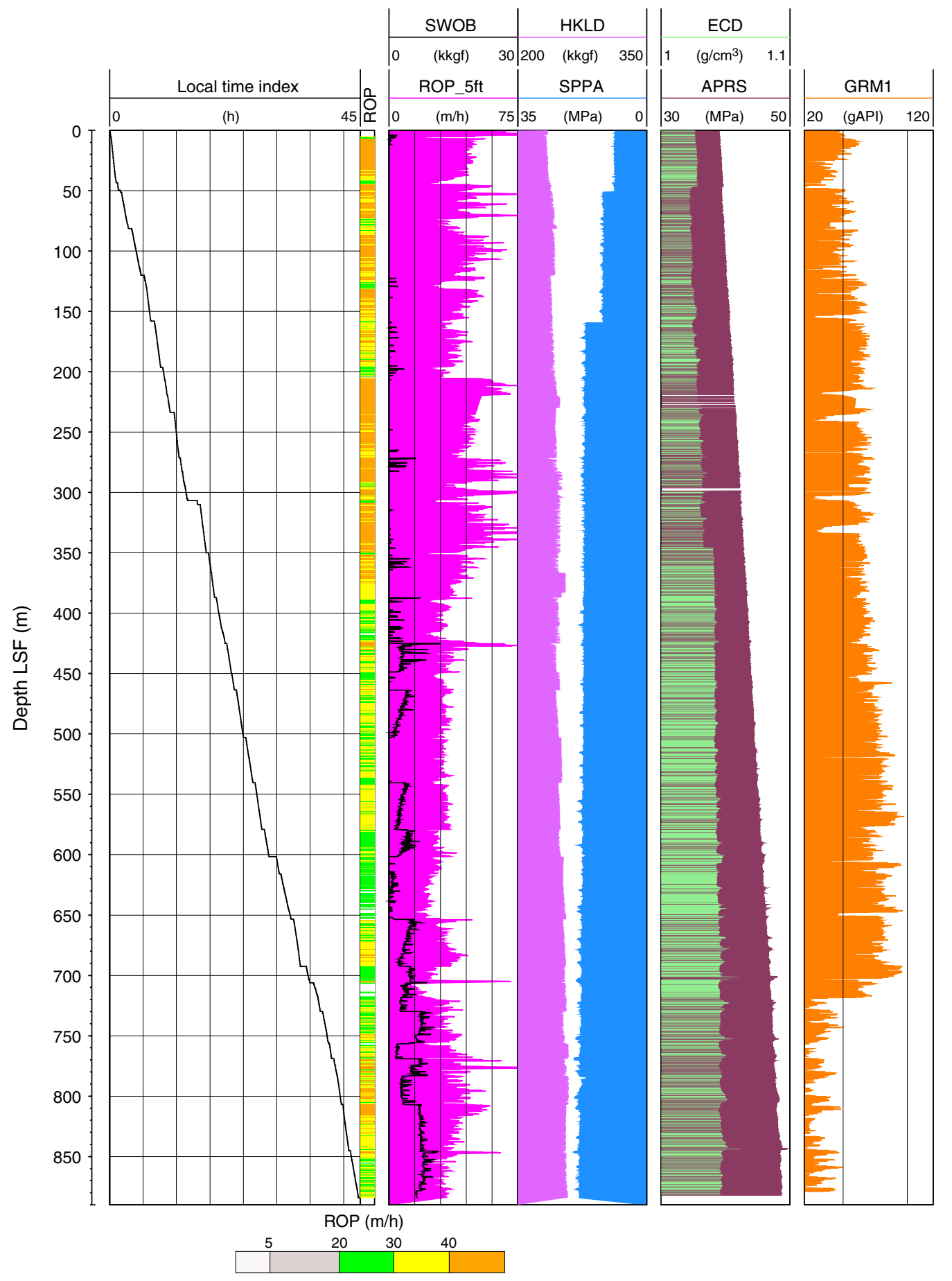


Figure F7. Plot of time-depth relationship, Hole C0006A. LSF = LWD depth below seafloor.

Time index (h)

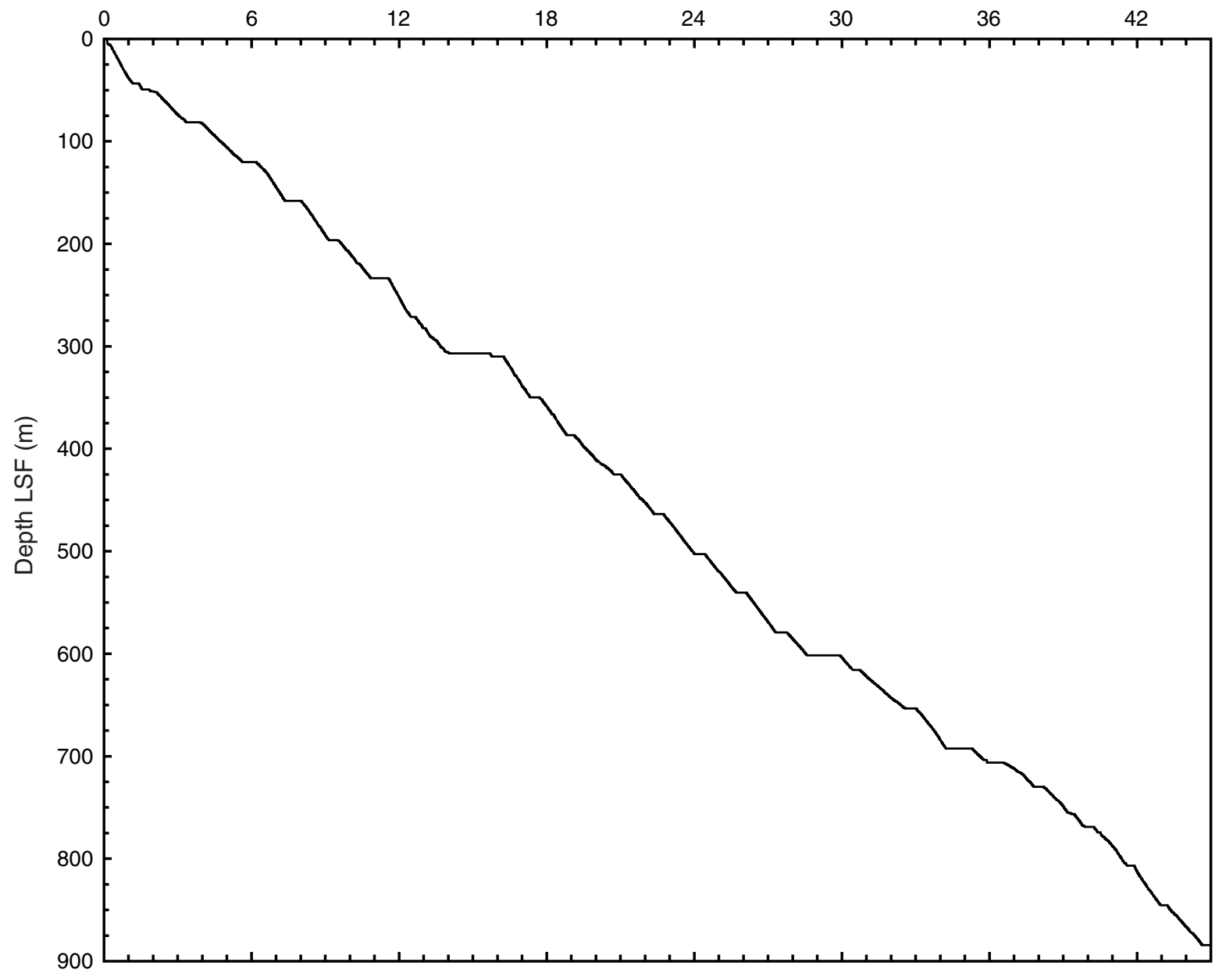


Figure F8. Control logs, Hole C0006B. LSF $=$ LWD depth below seafloor; ROP $=$ rate of penetration; $S W O B=$ surface weight on bit; HKLD = hook load; SPPA = standpipe pressure; DEVI = hole deviation; $\mathrm{ECD}=$ equivalent circulating density; APRS = average annular pressure; CC15, CC26, CC37, and CC48 = ADN ultrasonic calipers and color coded borehole condition indicators based on ADN calipers (Cxy = C15, C26, C37, and C48); GR_RAB $=$ Hole C0006B gamma ray log (geoVISION resistivity tool memory data) compared with Hole C0006A gamma ray $\log$ (GRM1; MWD real-time data).

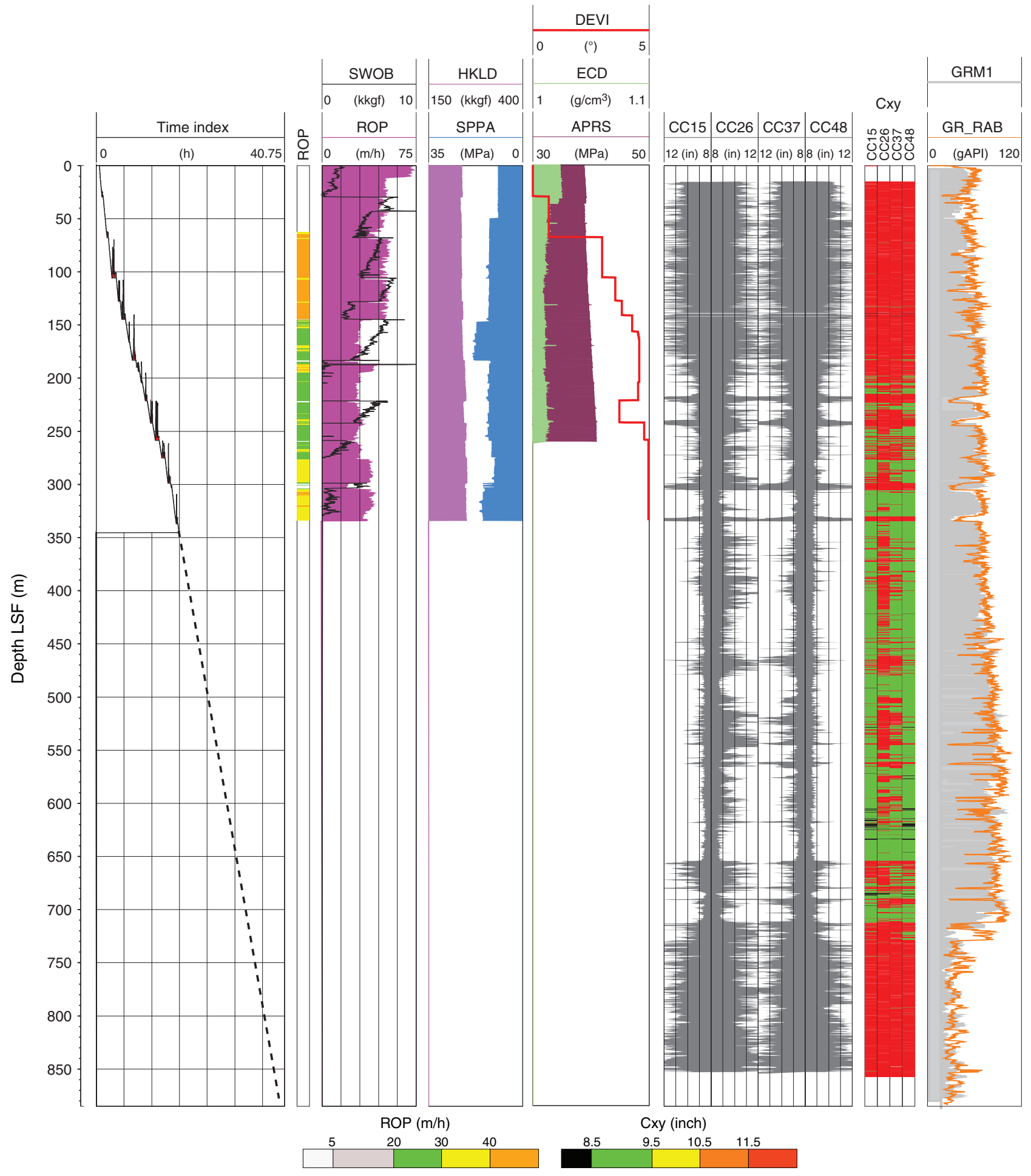


Figure F9. Mudline identification using geoVISION tool gamma ray and resistivity log (memory data, Hole C0006B. Mudline is identified by a break in gamma ray and resistivity logs at $3899.5 \mathrm{~m}$ drillers depth below rig floor (DRF). Note that resistivity data are plotted on a linear scale. LSF $=$ LWD depth below seafloor.

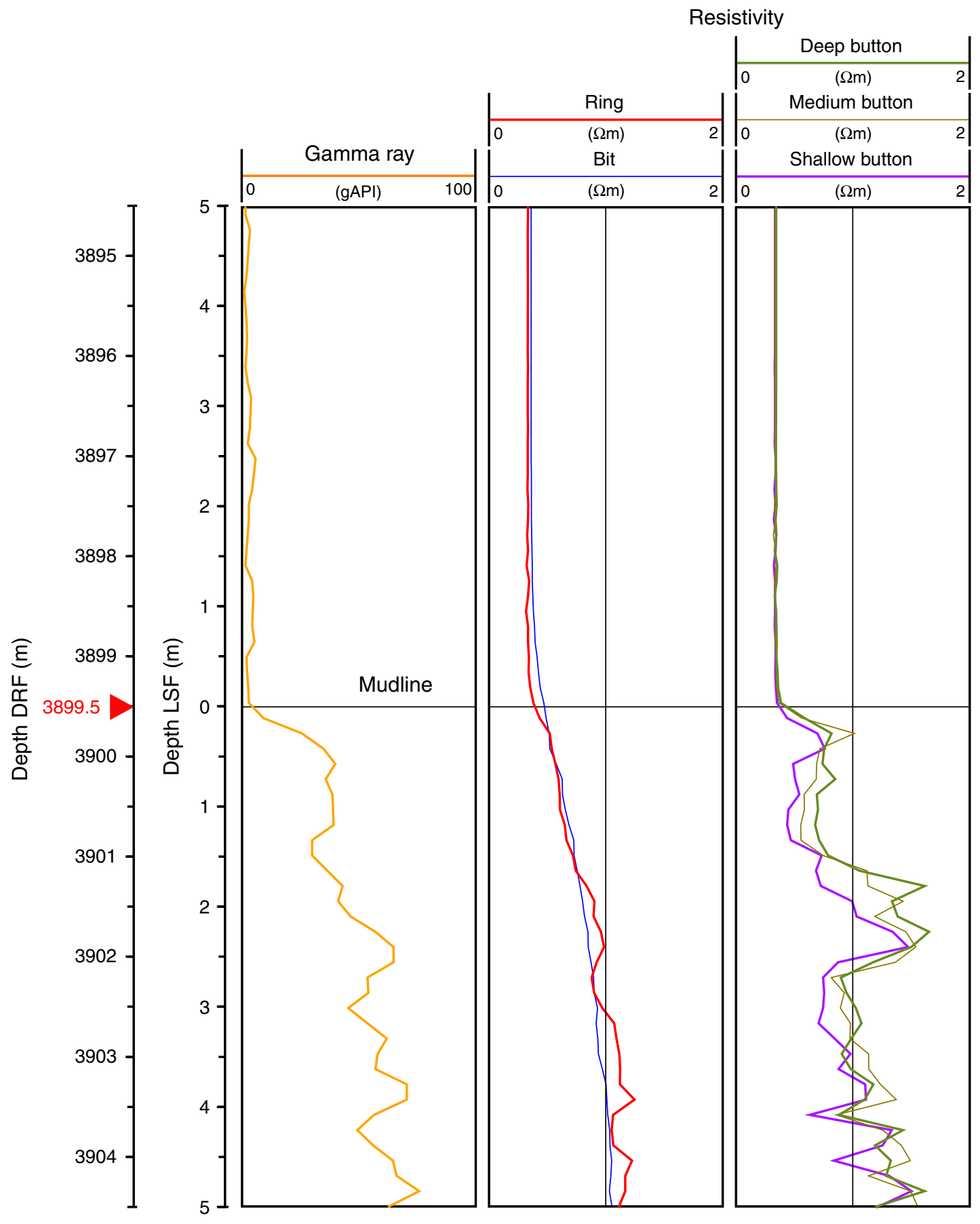


Figure F10. Geophysical logs, Hole C0006B. LSF = LWD depth below seafloor. ROP = rate of penetration; GR_RAB = gamma ray log (geoVISION resistivity [GVR] tool memory data); Cxy = ADN ultrasonic calipers C15, C26, C37, and C48; TAB_RAB_BD = time after bit of GVR deep button resistivity; TAB_RAB_BIT = time after bit of GVR bit resistivity; RES_BIT = bit resistivity; RES_RING = ring resistivity; RES_BD = deep button resistivity; RES_BM = medium button resistivity; RES_BS = shallow button resistivity; $V_{\mathrm{P}}=$ sonic compressional velocity $(P$ wave), DTCO $=\Delta \mathrm{T}$ compressional. (Figure shown on next page.) 
Figure F10 (continued). (Caption shown on previous page.)

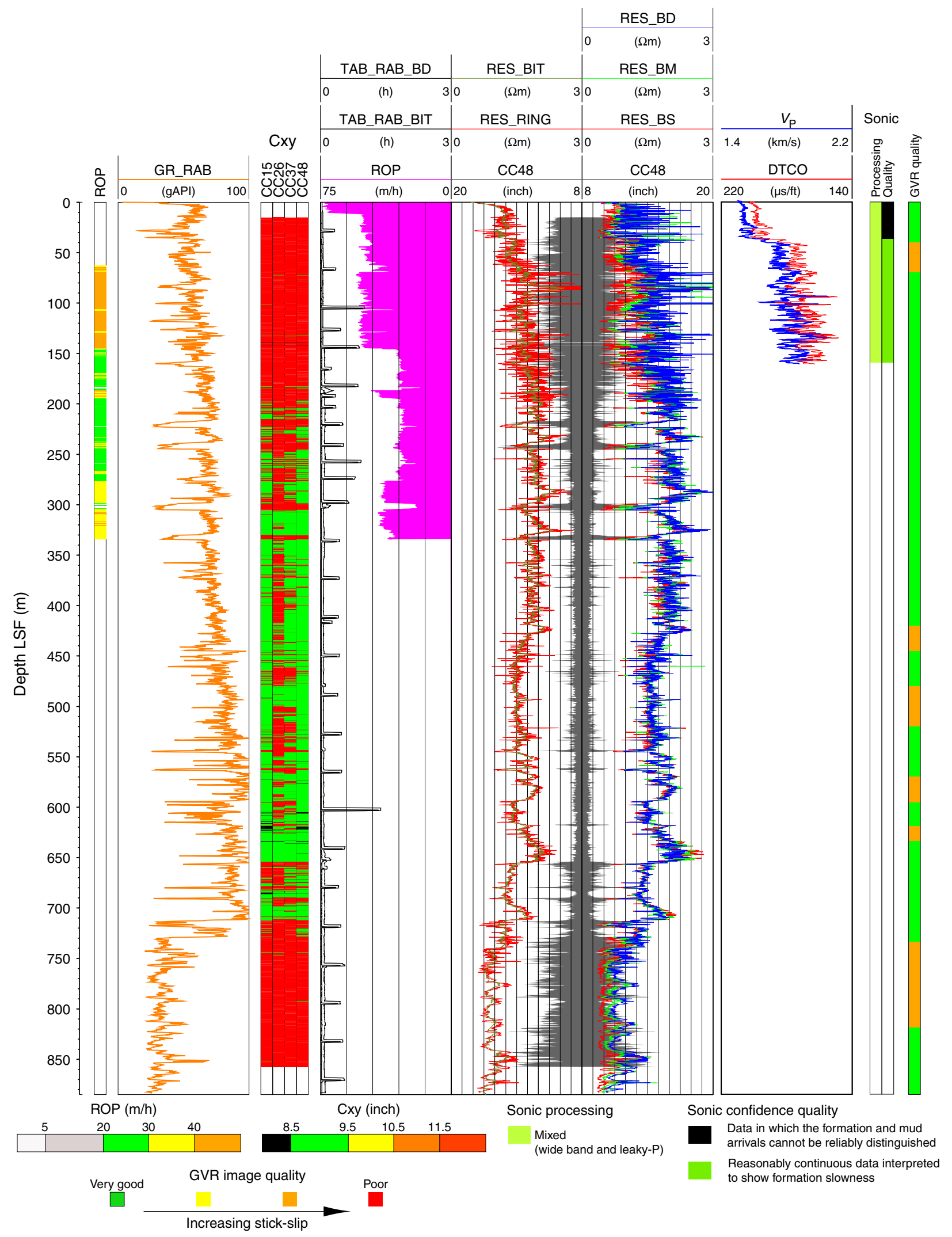


Figure F11. Plot of time-depth relationship, Hole C0006B. LSF = LWD depth below seafloor. LWD = logging while drilling, MWD = measurement while drilling.

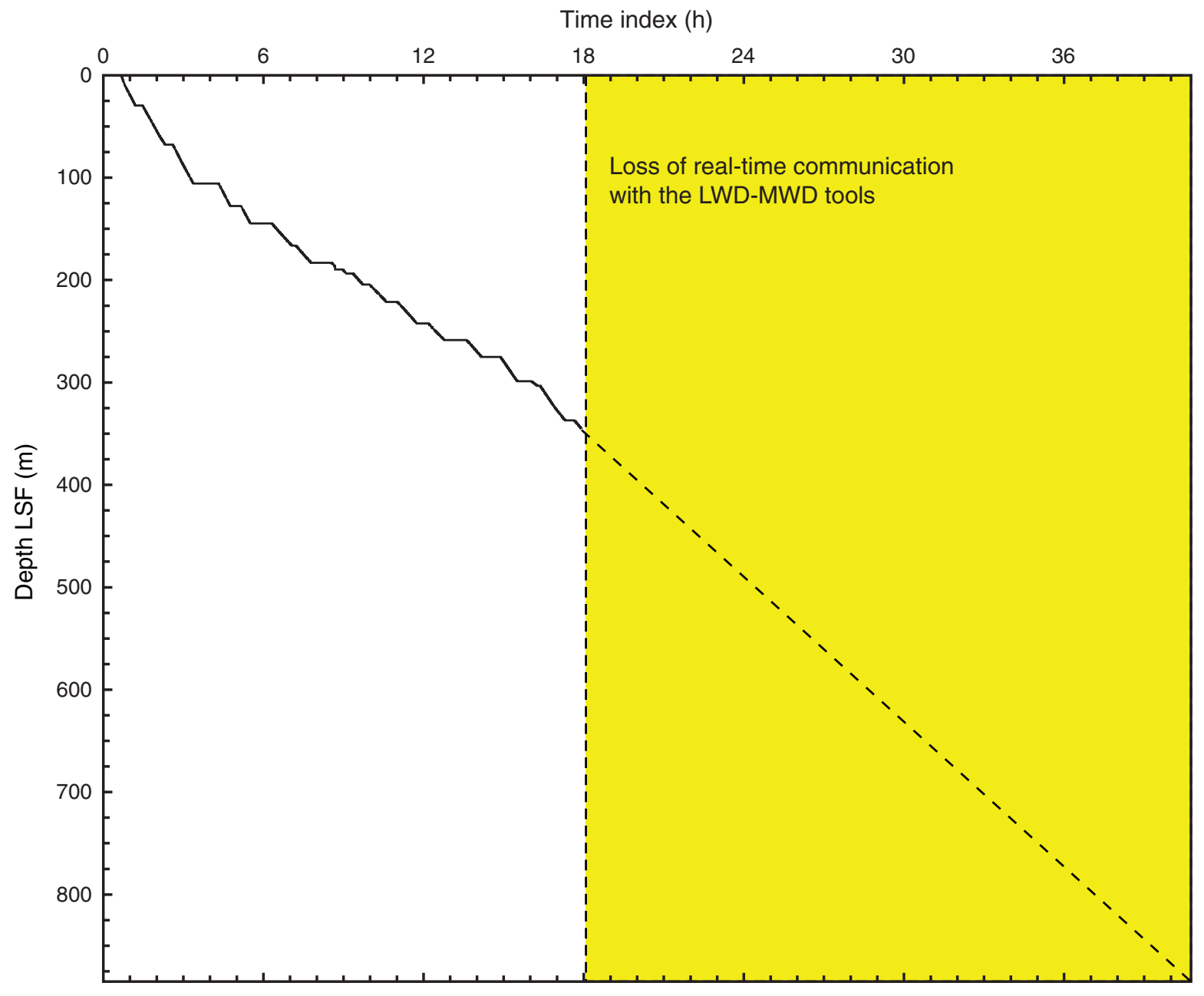


Figure F12. Statistical variation of gamma ray and ring resistivity exhibited by logging units and subunits.
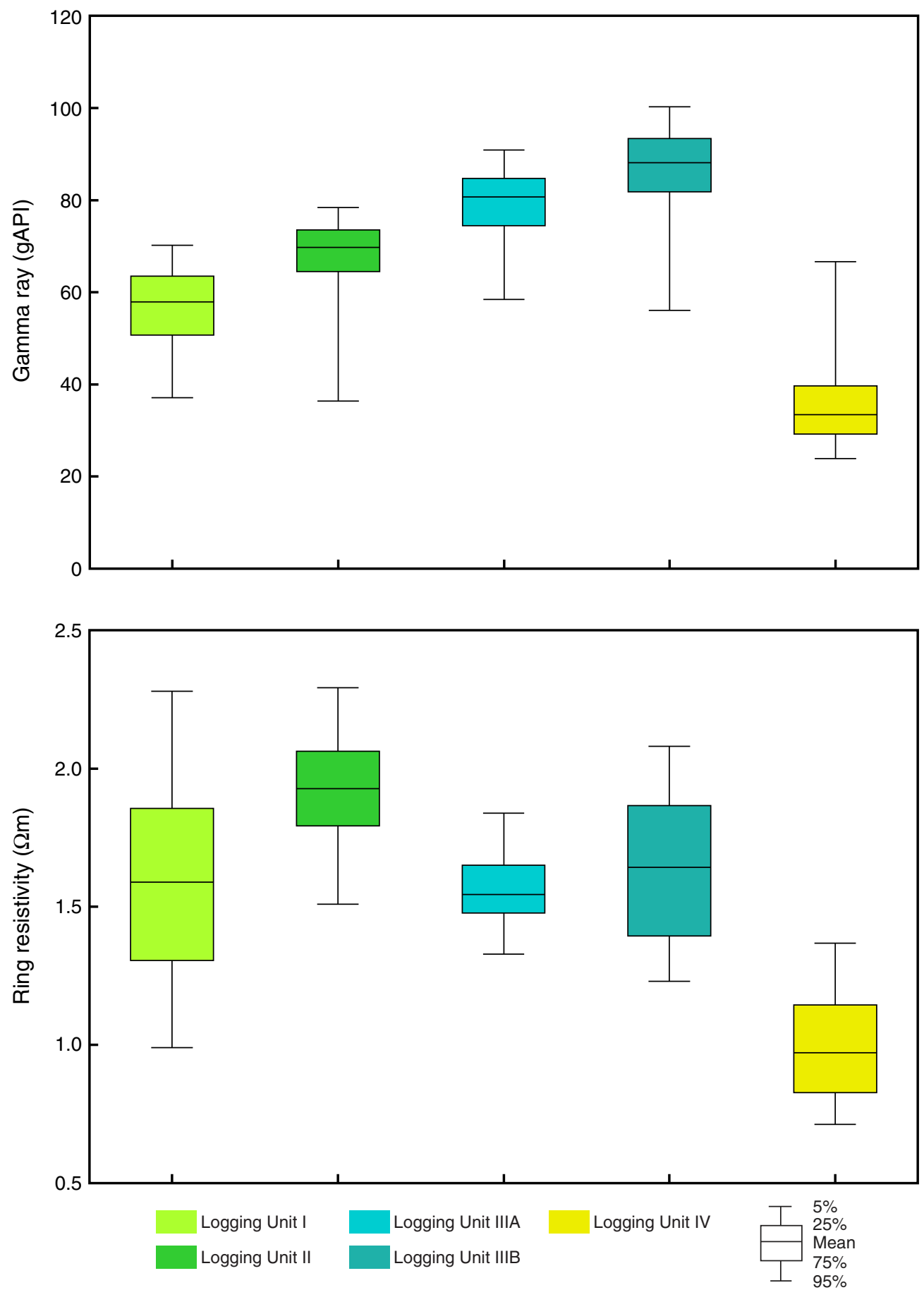
Figure F13. Plot of gamma ray vs. ring resistivity.

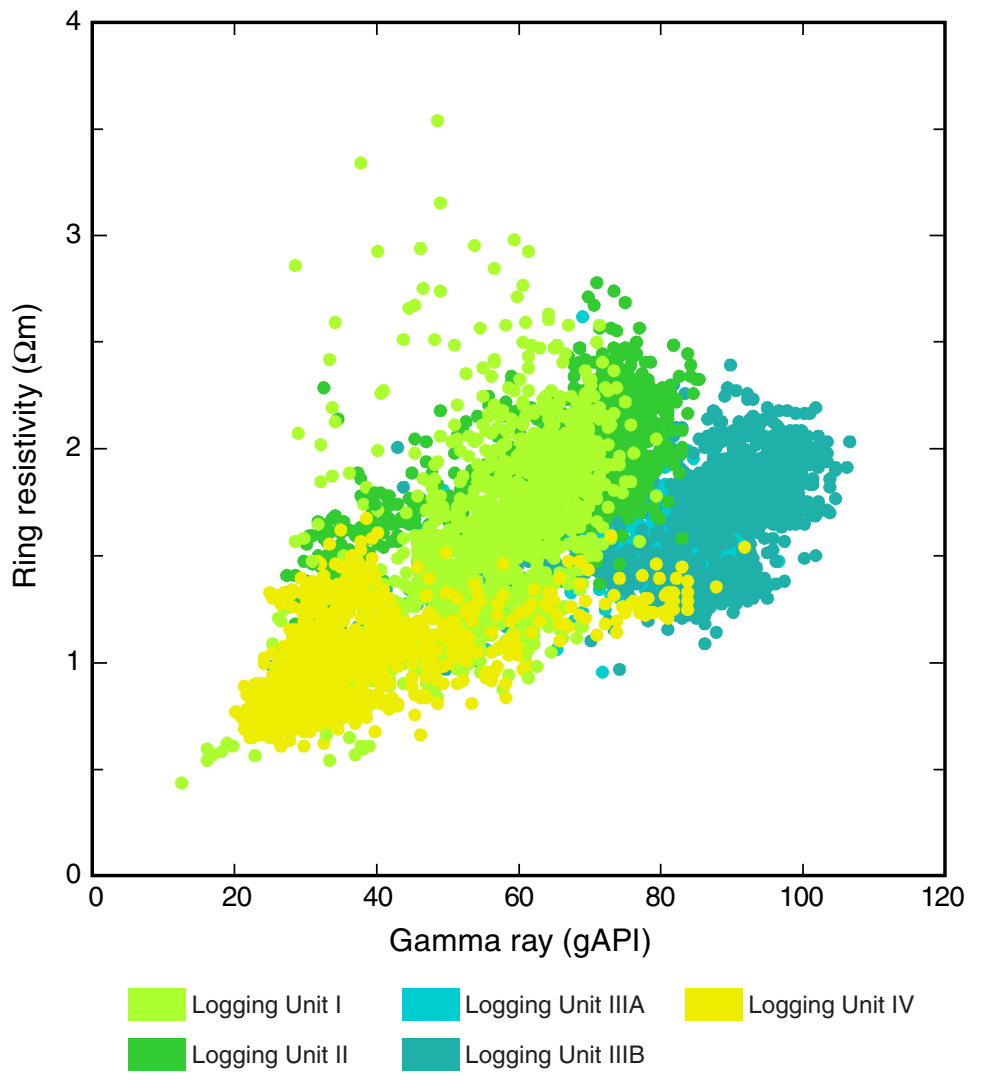


Figure F14. Summary plot of bedding dips derived from image data. LSF $=$ LWD depth below seafloor, RAB $=$ resistivity-at-the-bit.

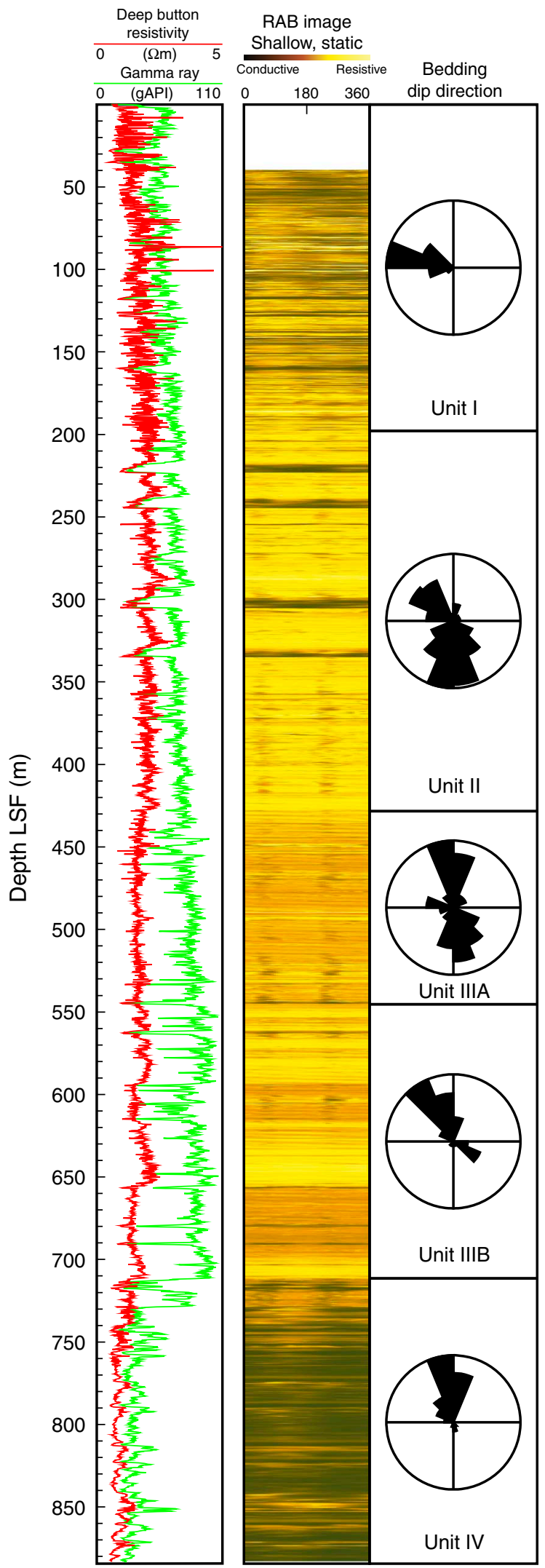


Figure F15. Logging Unit II logs. Upward-fining sequences in four sand layers are clearly imaged by resistivityat-the-bit (RAB) images and exhibited by gamma ray (GR) and resistivity log curves. An inferred thrust fault at $254 \mathrm{~m}$ LWD depth below seafloor (LSF) is shown.

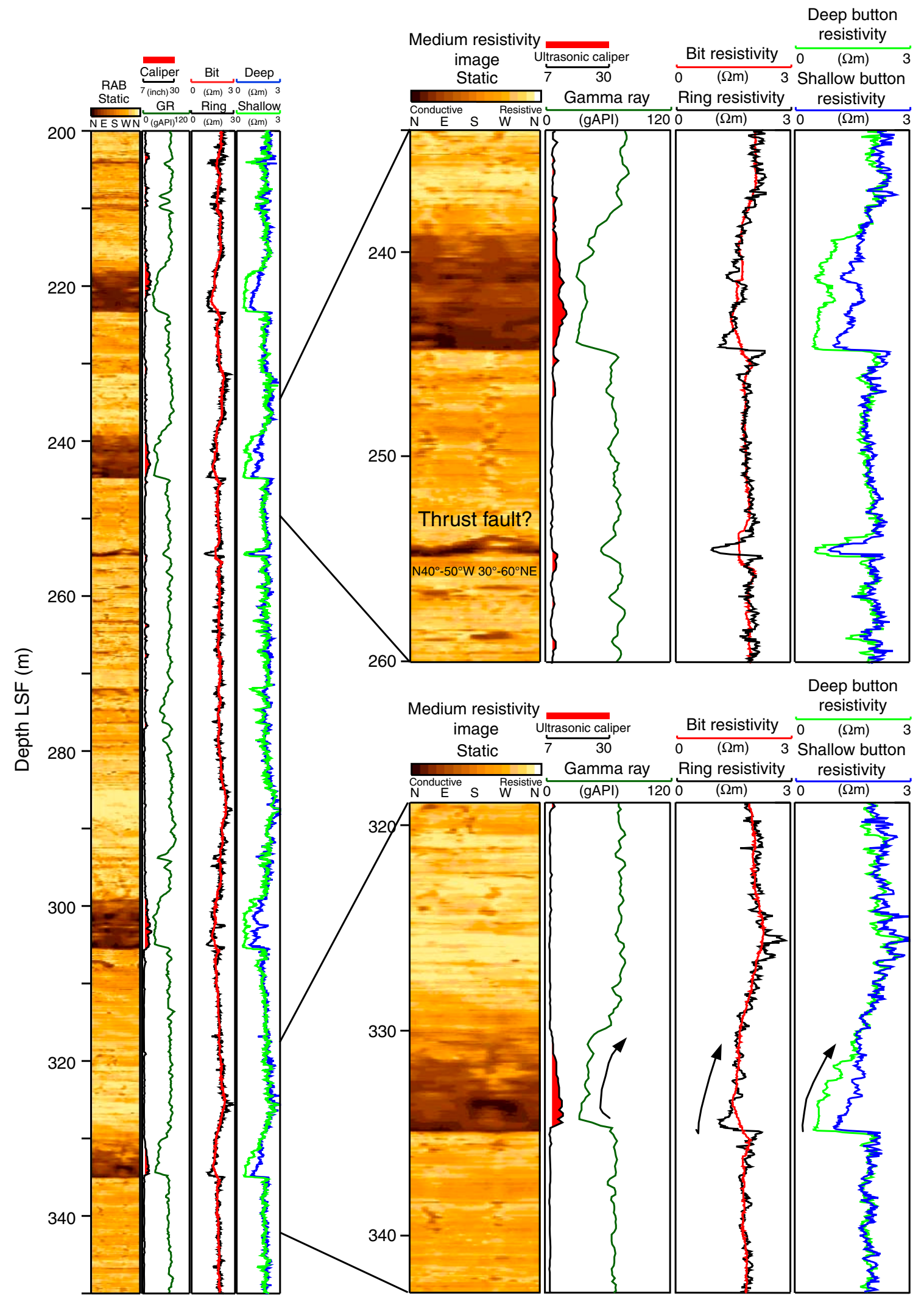


Figure F16. Ring and bit resistivity and smoothed shallow, medium, and deep button resistivity logs. Smoothing results from a moving average of the resistivity values using a 21-point window. LSF $=$ LWD depth below seafloor.

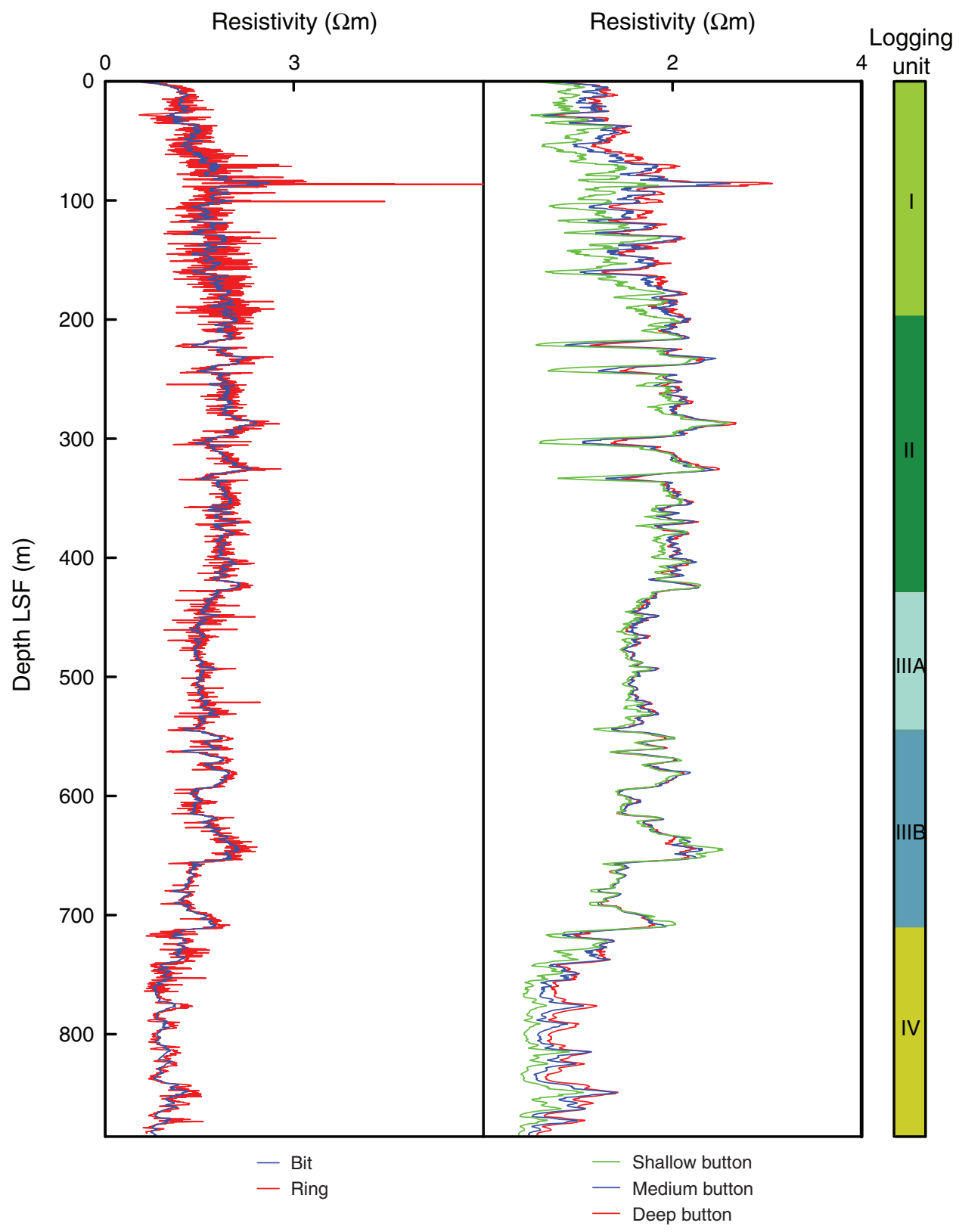


Figure F17. Plots of (A) bit vs. ring resistivity and (B) shallow vs. deep button resistivity. Black line $=$ line of unit slope passing through origin.
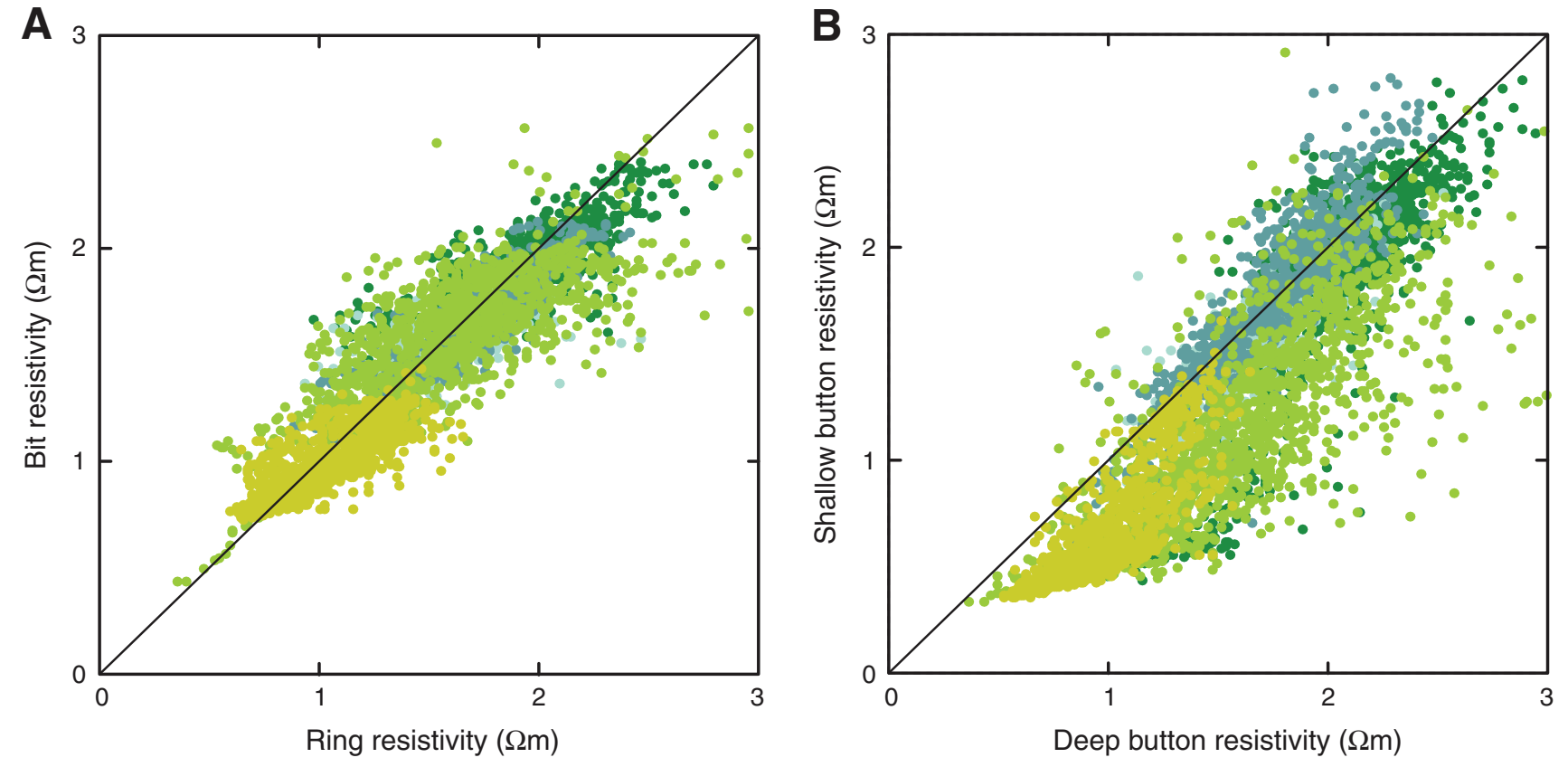

- Logging Unit I • Logging Unit II • Logging Unit IIIA • Logging Unit IIIB • Logging Unit IV 
Figure F18. Bit and ring resistivity-derived porosity and density calculated from porosity using Archie's law with parameters $a=1$ and $m=2.4$ (see "Physical properties" for discussion of possible lithology dependence). LSF $=$ LWD depth below seafloor.

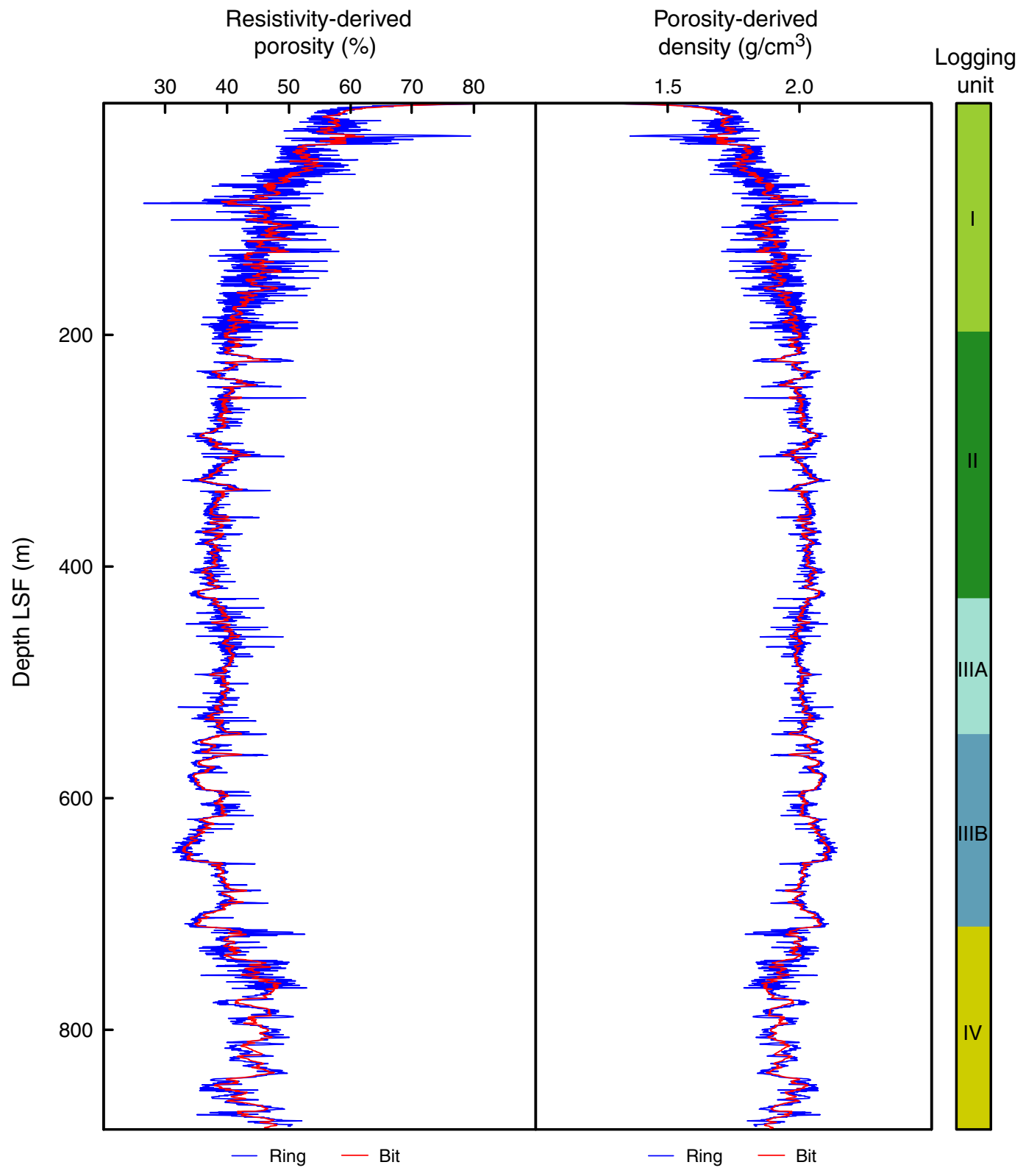


Figure F19. Comparison between sonic $P$-wave velocity and resistivity, Hole C0006A. LSF $=$ LWD depth below seafloor.

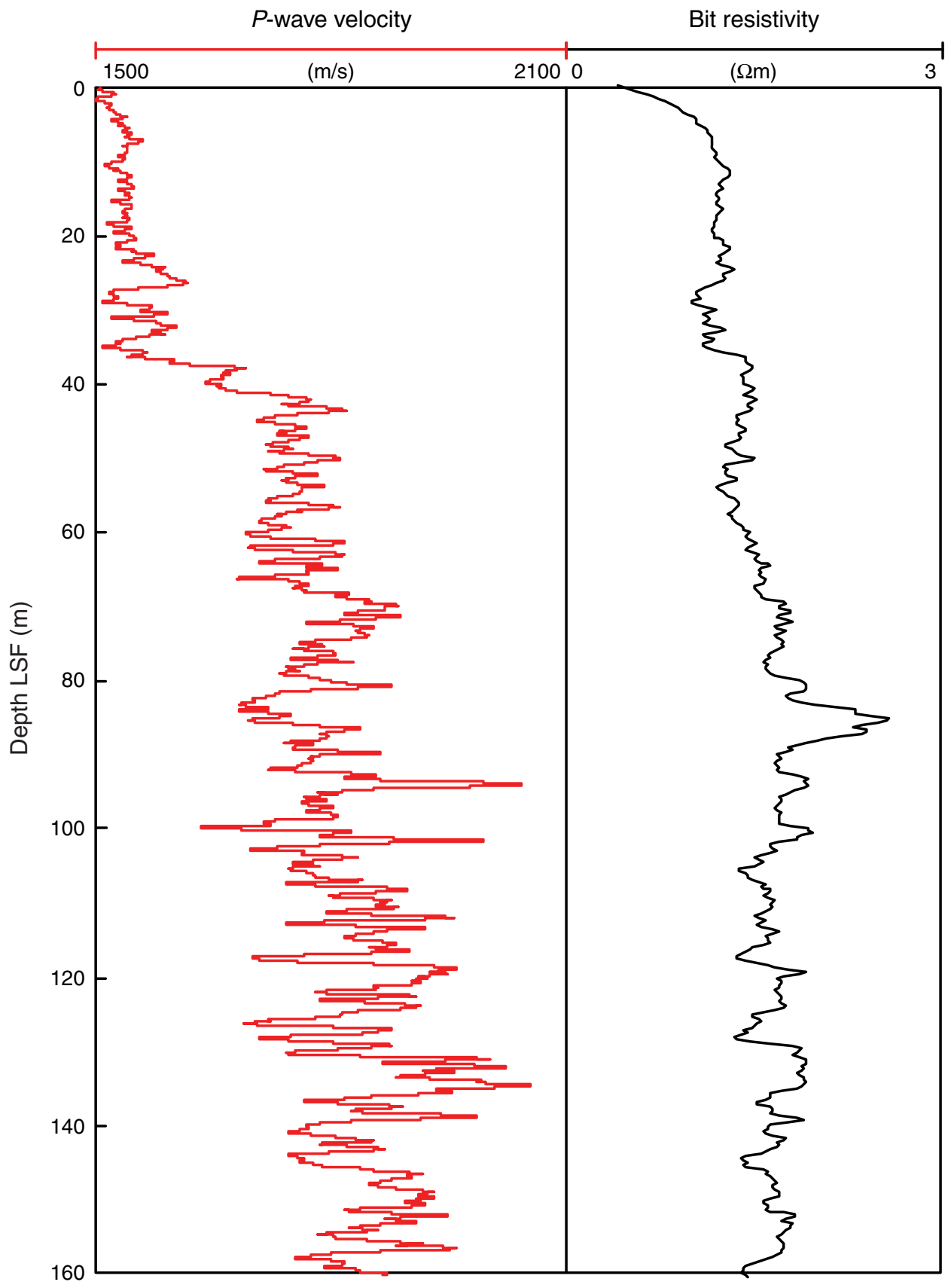


Figure F20. Plot of sonic P-wave velocity vs. resistivity, Hole C0006A.

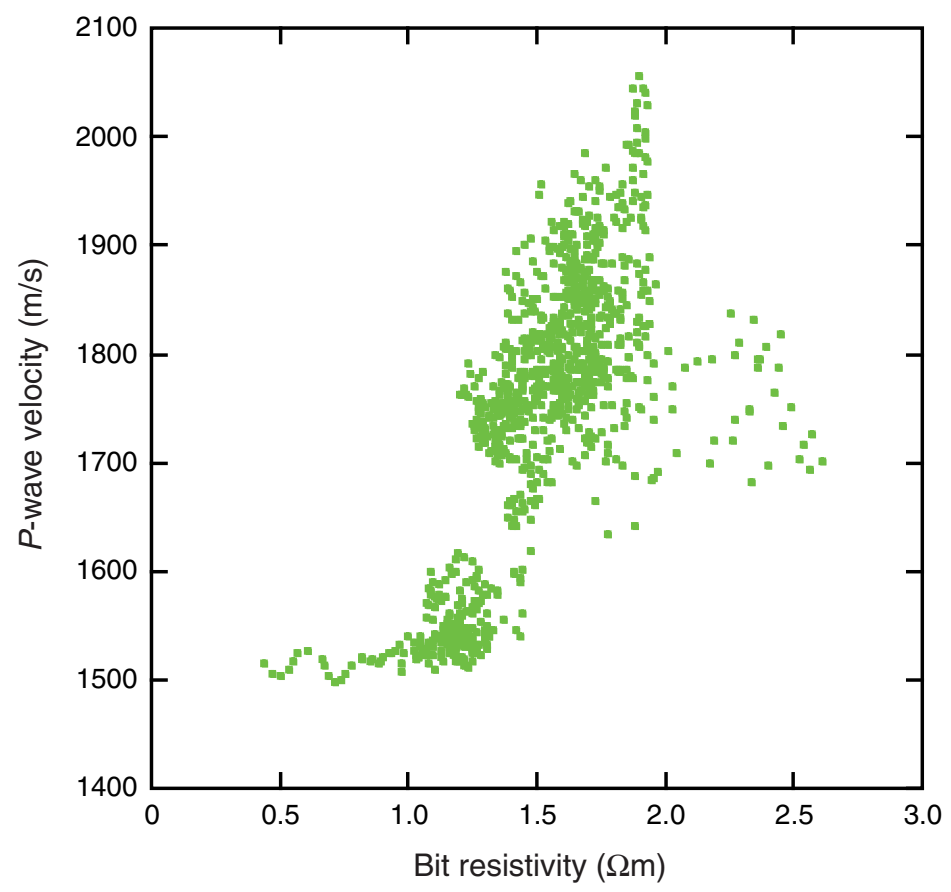


Figure F21. Vertically compressed shallow resistivity image (dynamic normalization) of borehole showing trends in bedding and fractures. Tadpole lines = dip direction of plane. LSF $=$ LWD depth below seafloor.

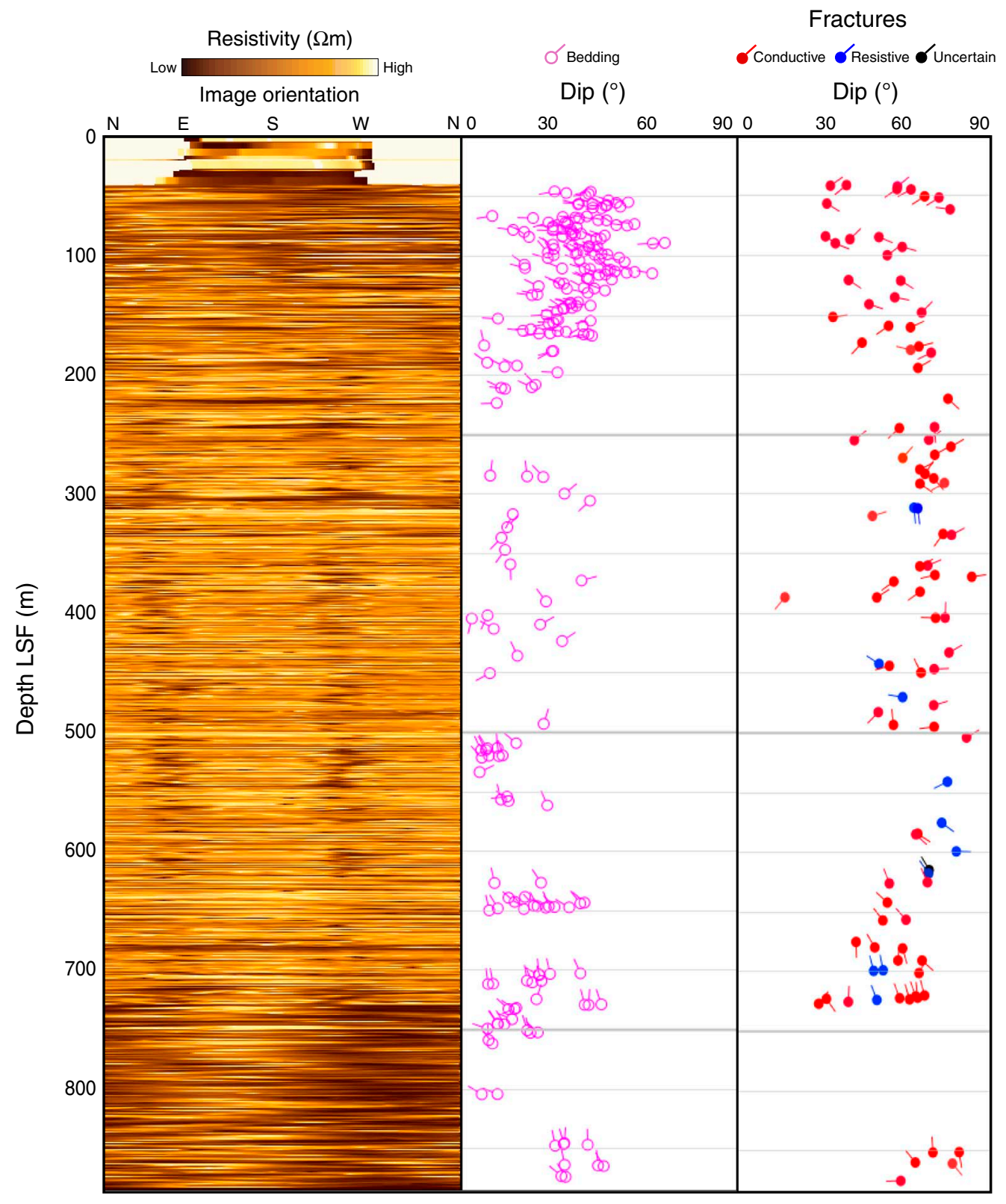


Figure F22. Bedding orientations in each logging unit. Left column = equal area lower hemisphere projections of poles to bedding, right column $=$ rose diagrams representing azimuths (shown as dip direction $-90^{\circ}$ ) preserving dip direction information. Note dominantly westerly dip of bedding in logging Unit I and northwestward dips of bedding in logging Units III and IV. LSF = LWD depth below seafloor. TD = total depth.

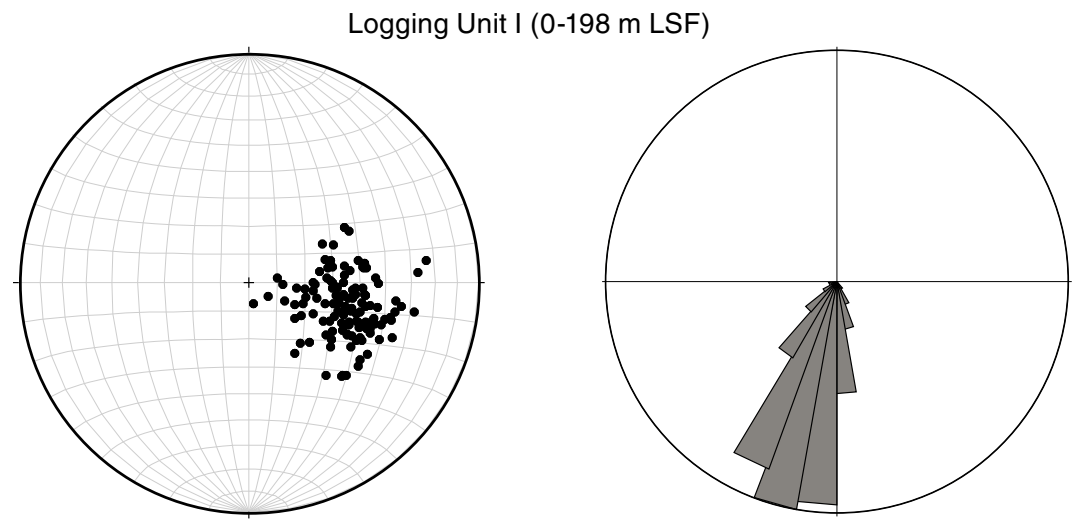

Logging Unit II (198-428 m LSF)
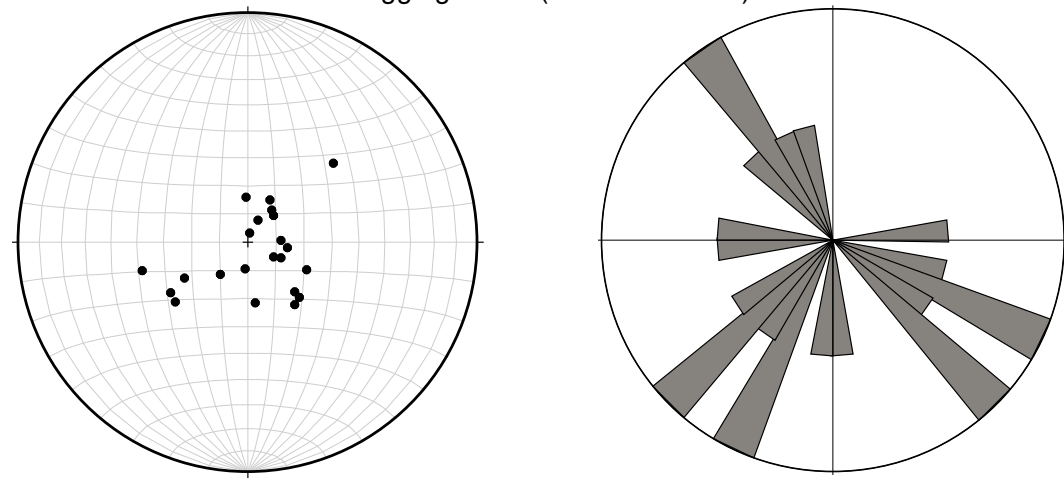

Logging Unit III (428-711 m LSF)
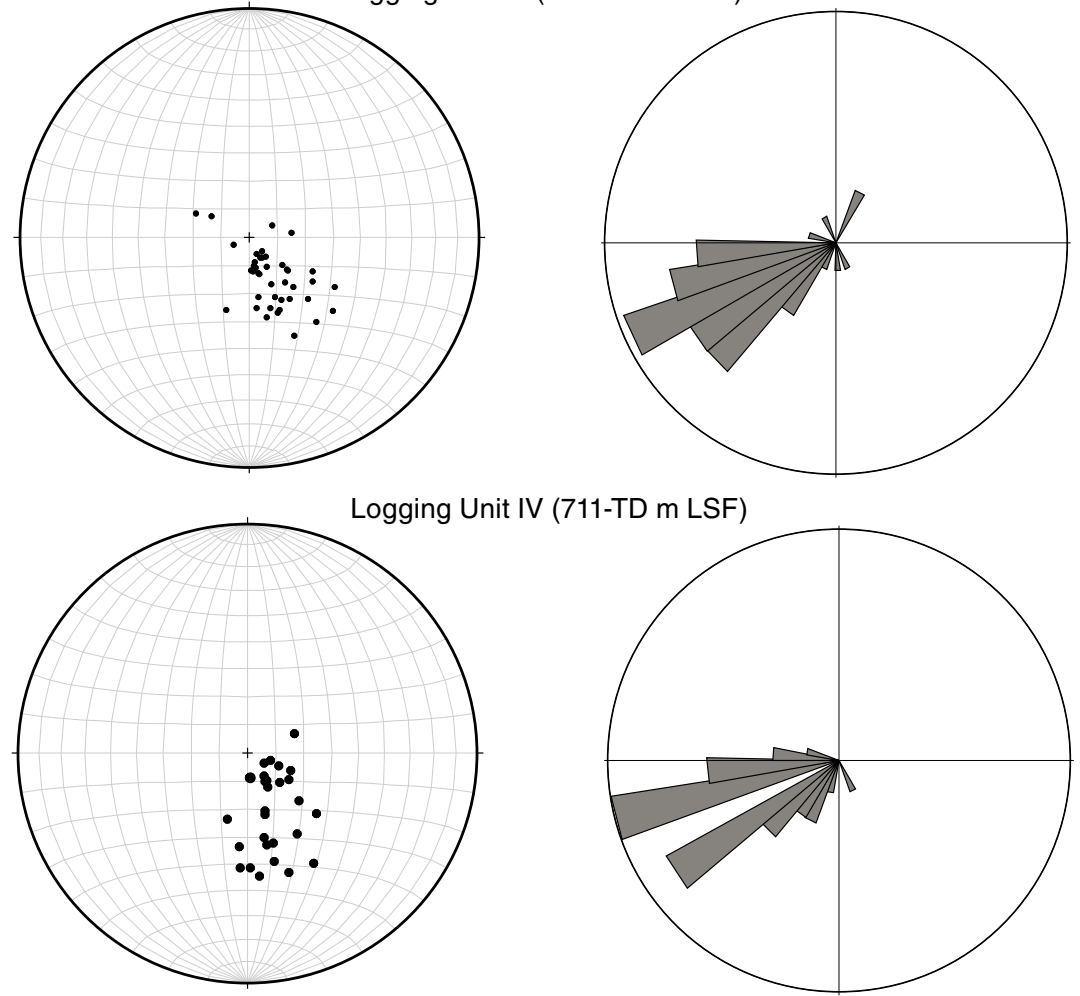
Figure F23. Uninterpreted and interpreted image of conductive fracture with an immediately overlying fold at 656-657 m LWD depth below seafloor (LSF). Conductive fracture may correlate with seismic interpretation of main frontal thrust.

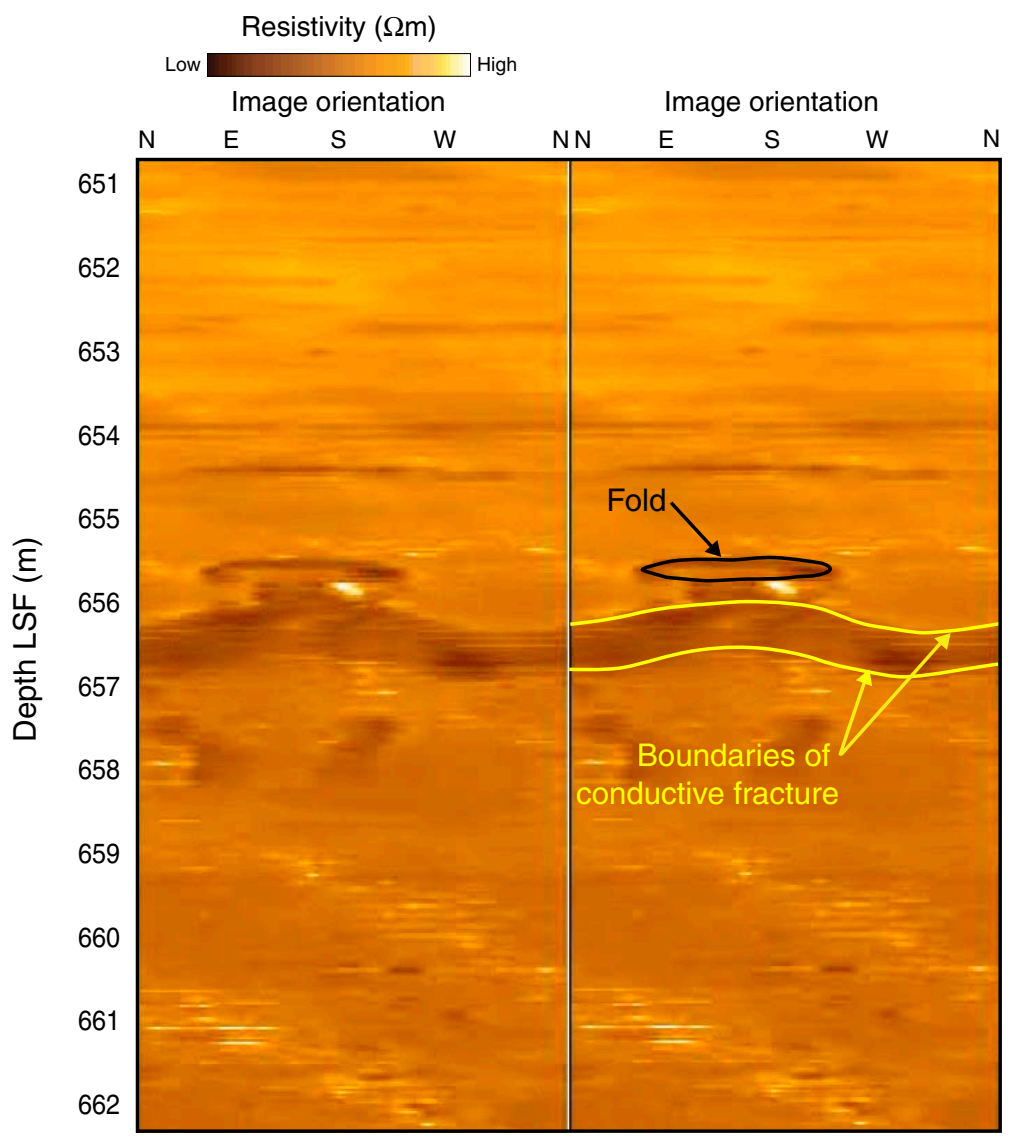


Figure F24. Fracture orientations in each logging unit. Left column = equal area lower hemisphere projections of poles to fracture planes, right column $=$ rose diagrams showing fracture strikes (shown as dip direction $-90^{\circ}$ ) preserving dip direction information. Note predominance of northwest fracture orientations in logging Units I and II in contrast to northeast-southwest orientations of logging Units III and IV. LSF = LWD depth below seafloor. $\mathrm{TD}=$ total depth.
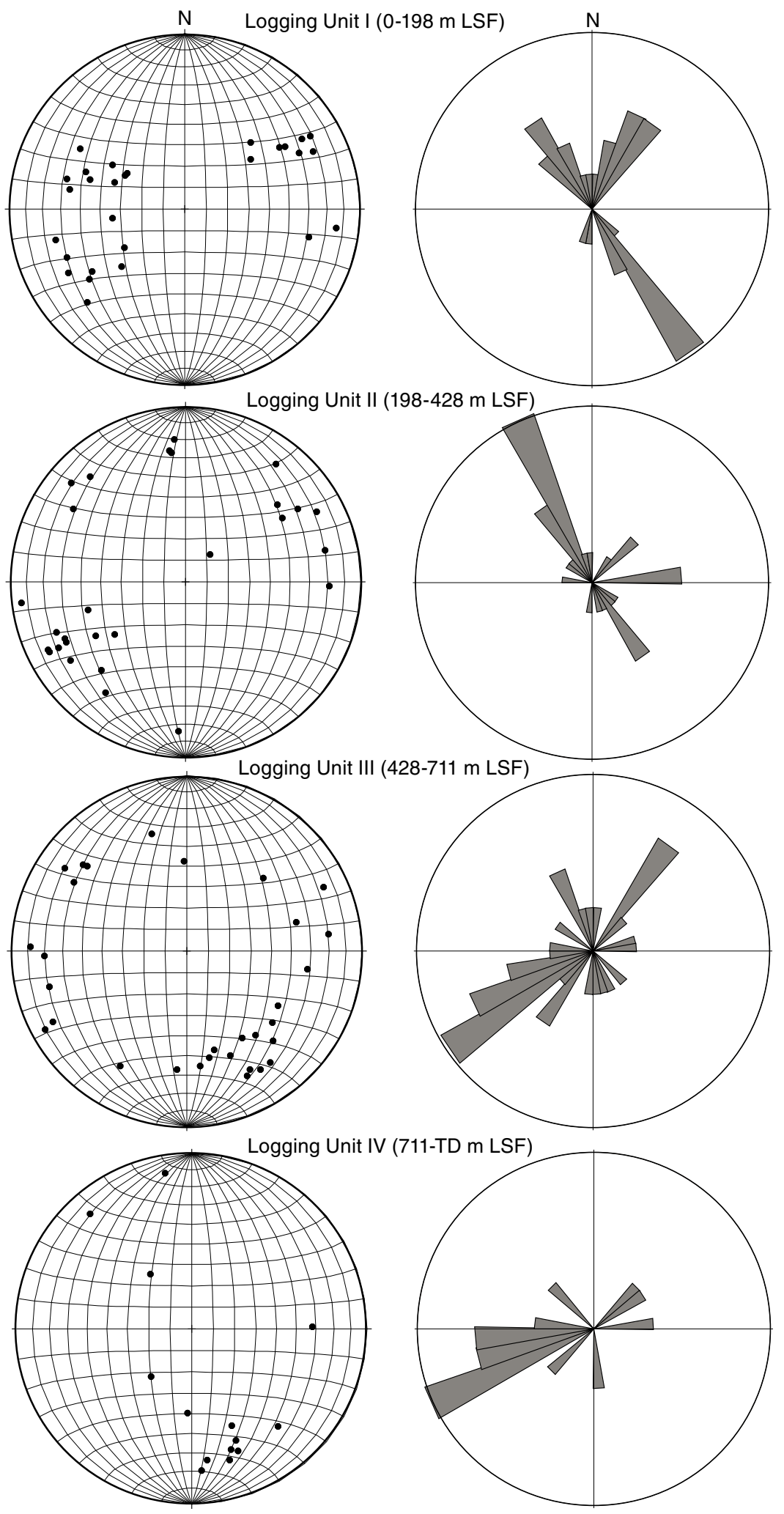
Figure F25. Distribution of borehole breakout azimuths and widths. A. Histogram of breakout azimuths. B. Variation of breakout azimuths with depth. C. Histogram of breakout widths. D. Variation of breakout widths with depth. Note decreasing width with depth. LSF = LWD depth below seafloor.
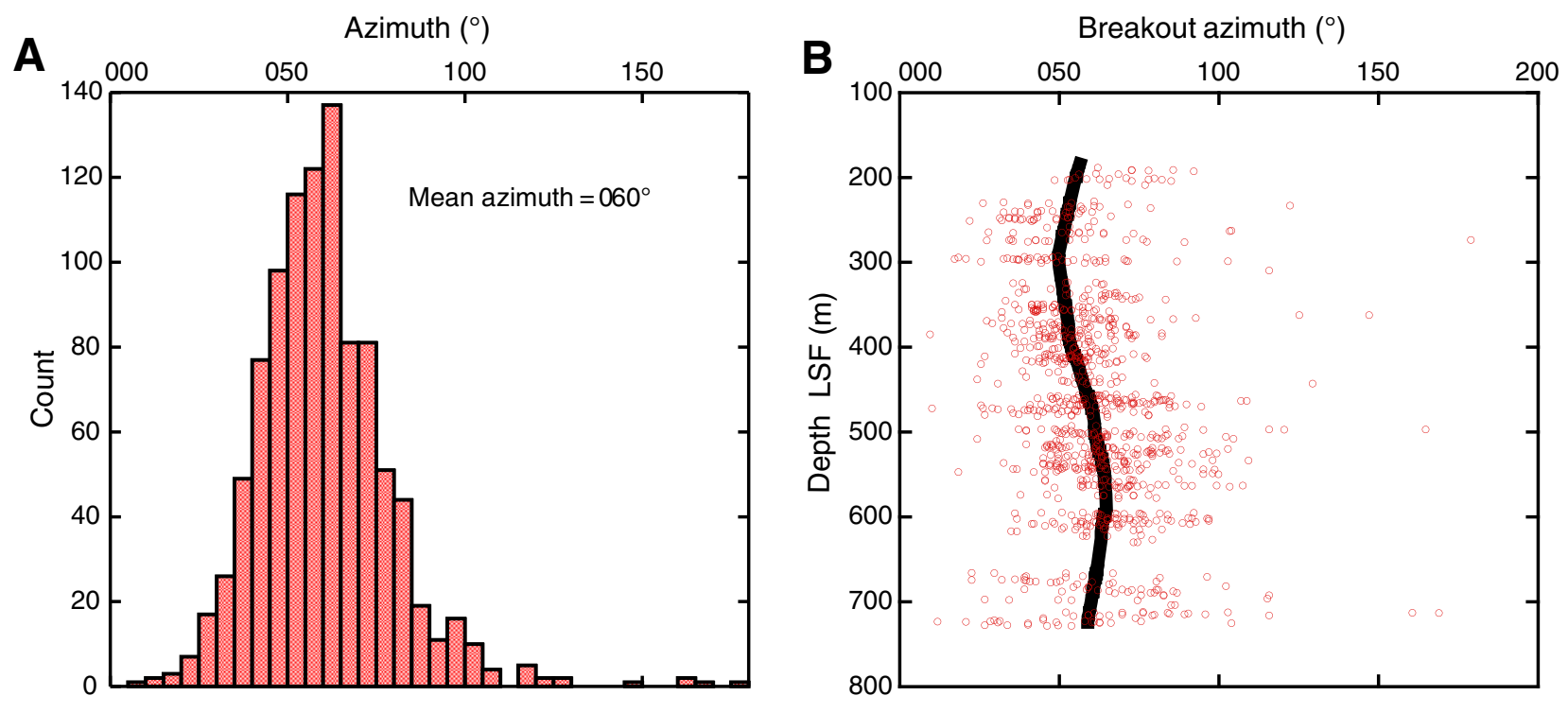

Width $\left({ }^{\circ}\right)$
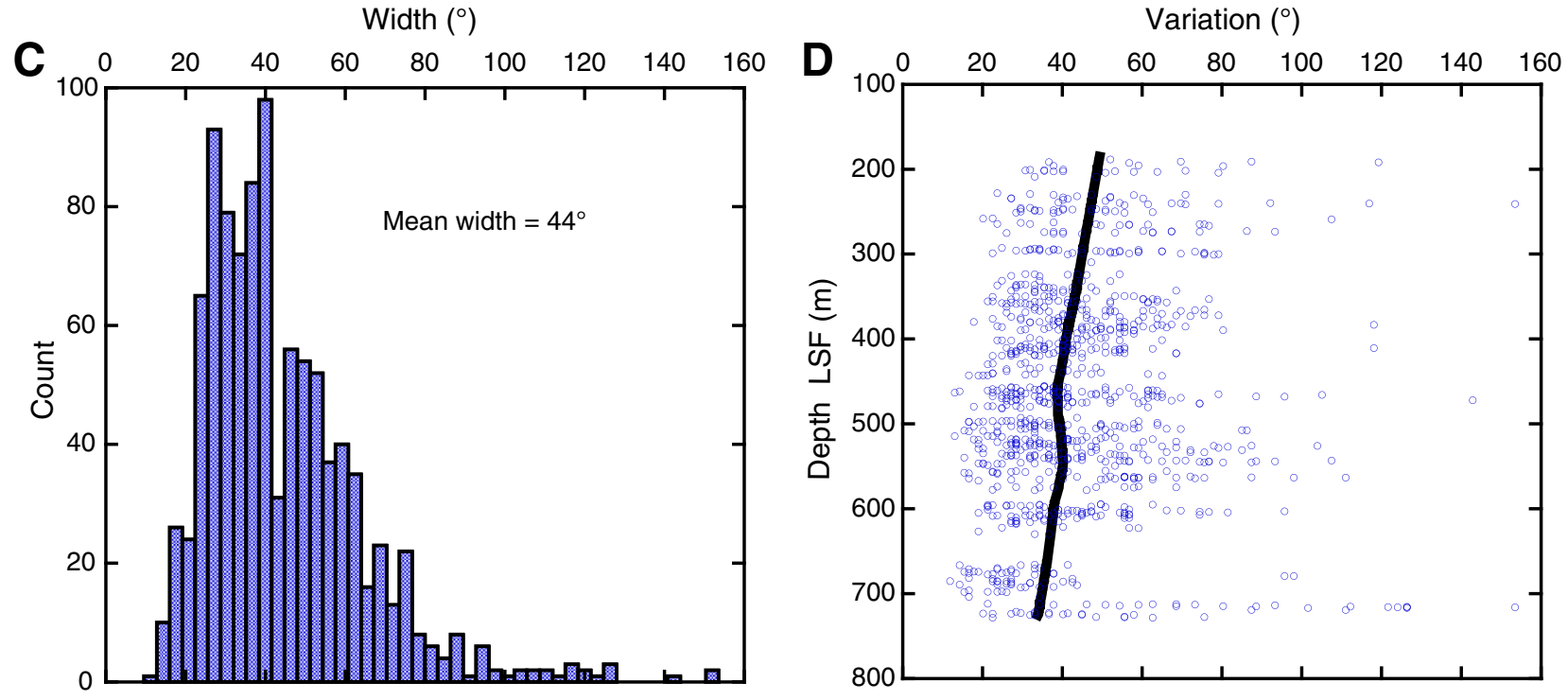
Figure F26. Orientation of $S_{\mathrm{Hmax}}$. Note consistency of trend across accretionary prism at Sites C0006, C0004, and C0001 and contrasting orientation in forearc basin at Site C0002. Orientations at Site C0002 represent change in $S_{\text {Hmax }}$ from shallow depths in forearc basin (red lines) to near base of hole in underlying accretionary prism (blue line). Convergence vector represents range from Miyasaki and Heki (2001), Heki (2007), and Seno et al. (1993). GPS = Global Positioning System.

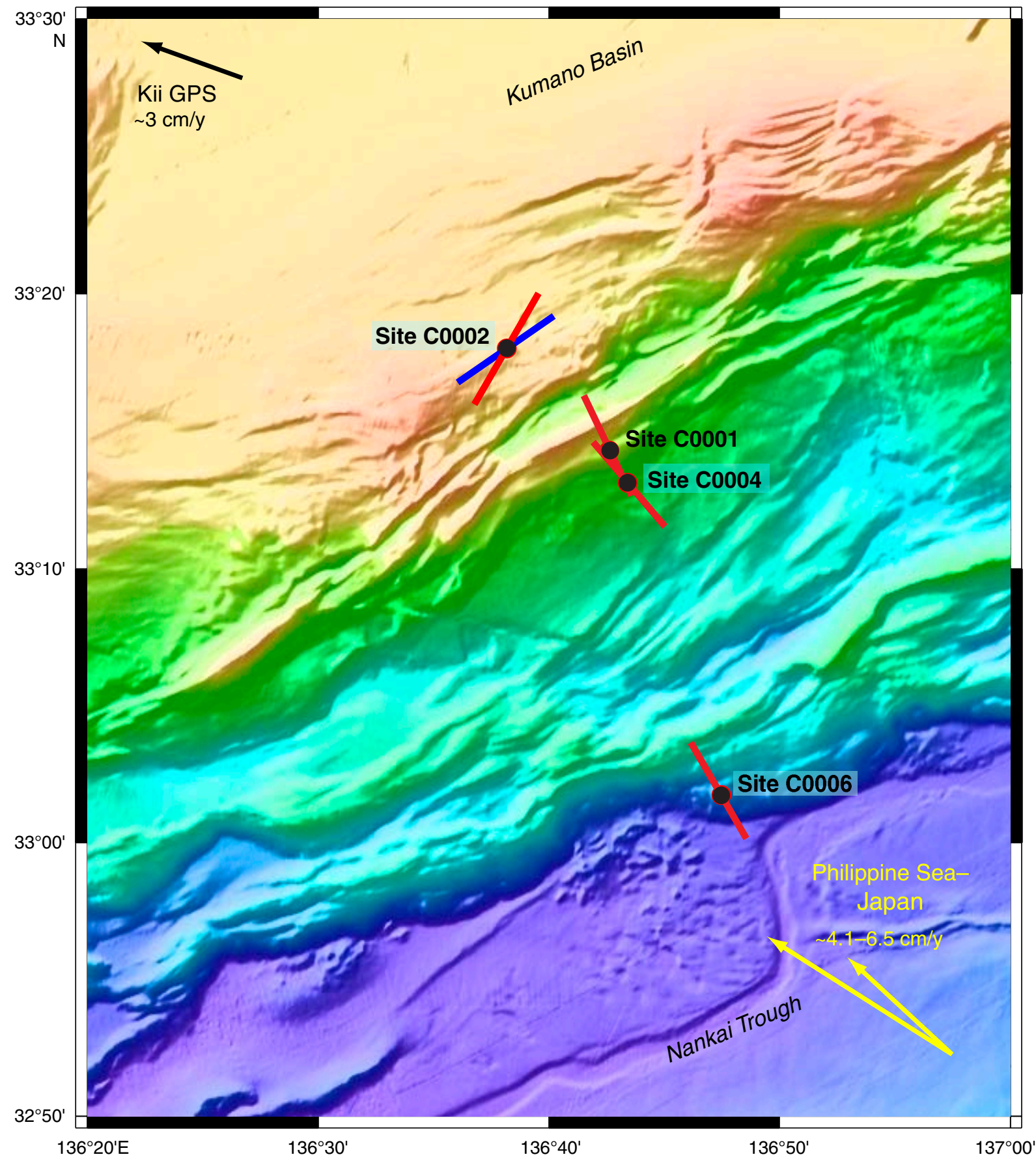


Figure F27. Seismic reflection section (check shot-corrected depth section for prestack depth-migrated Inline 2434), Site C0006. A. Uninterpreted (red = positive amplitudes, black = negative amplitudes). B. Interpreted (black $=$ positive amplitudes, white $=$ negative amplitudes). Red $=$ thrust faults (with the main frontal thrust being the deepest fault), blue and yellow $=$ key reflections correlated with features in the LWD data. VE $=$ vertical exaggeration.
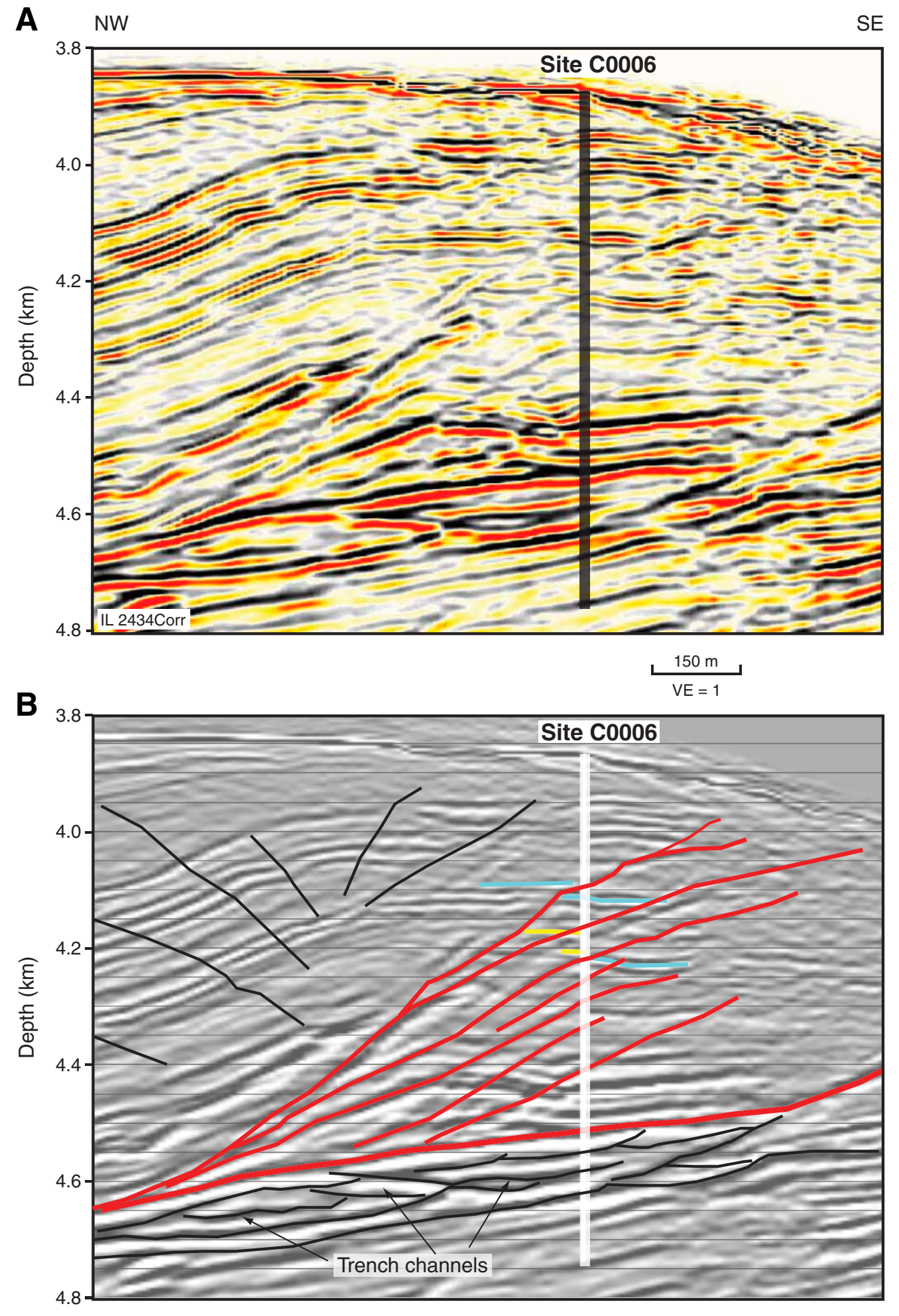
Figure F28. Check shot display showing clear first arrivals from seismicVISION tool. LSF = LWD depth below seafloor.

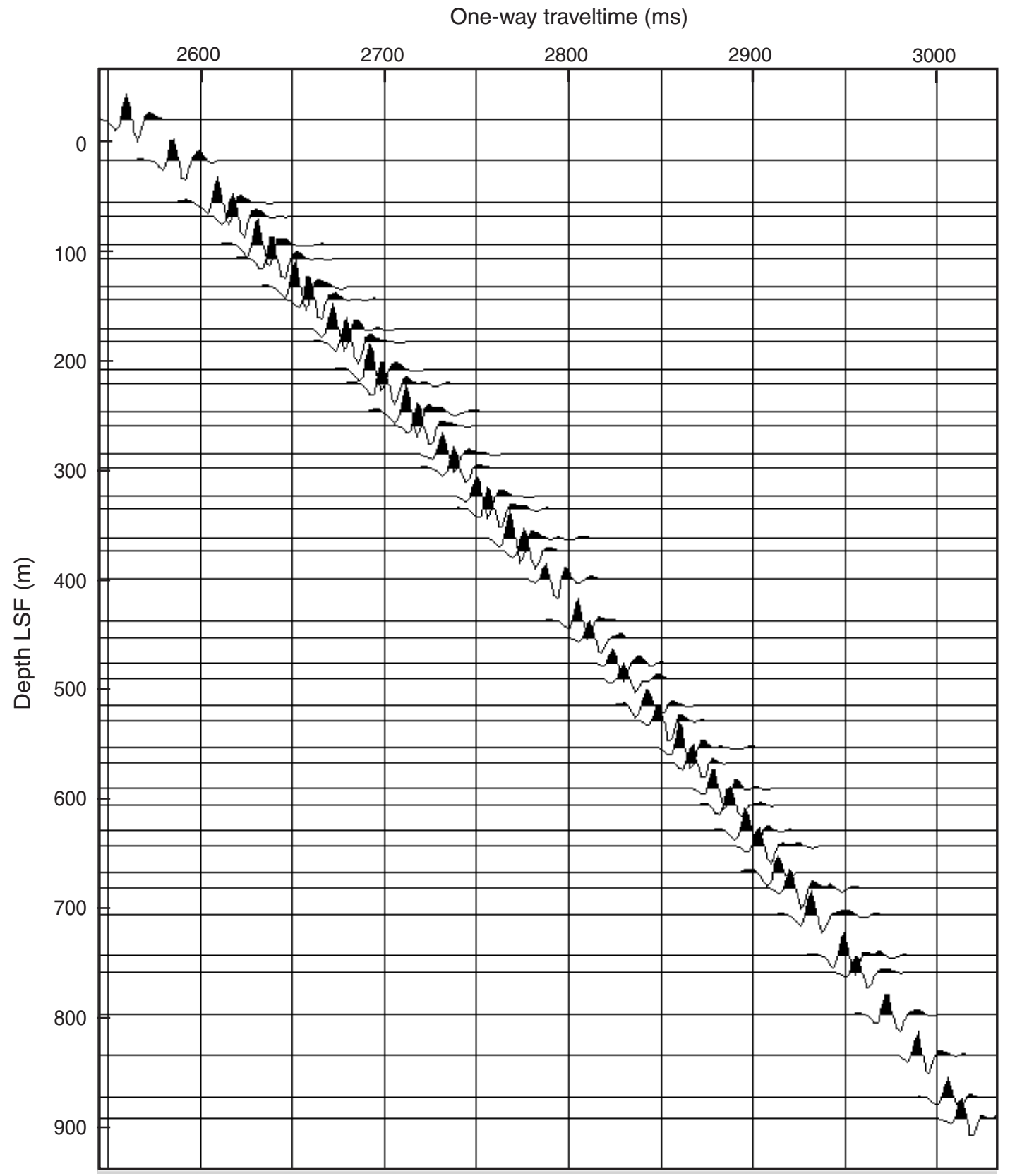


Figure F29. Smoothed and raw check shot interval velocities. LSF = LWD depth below seafloor.

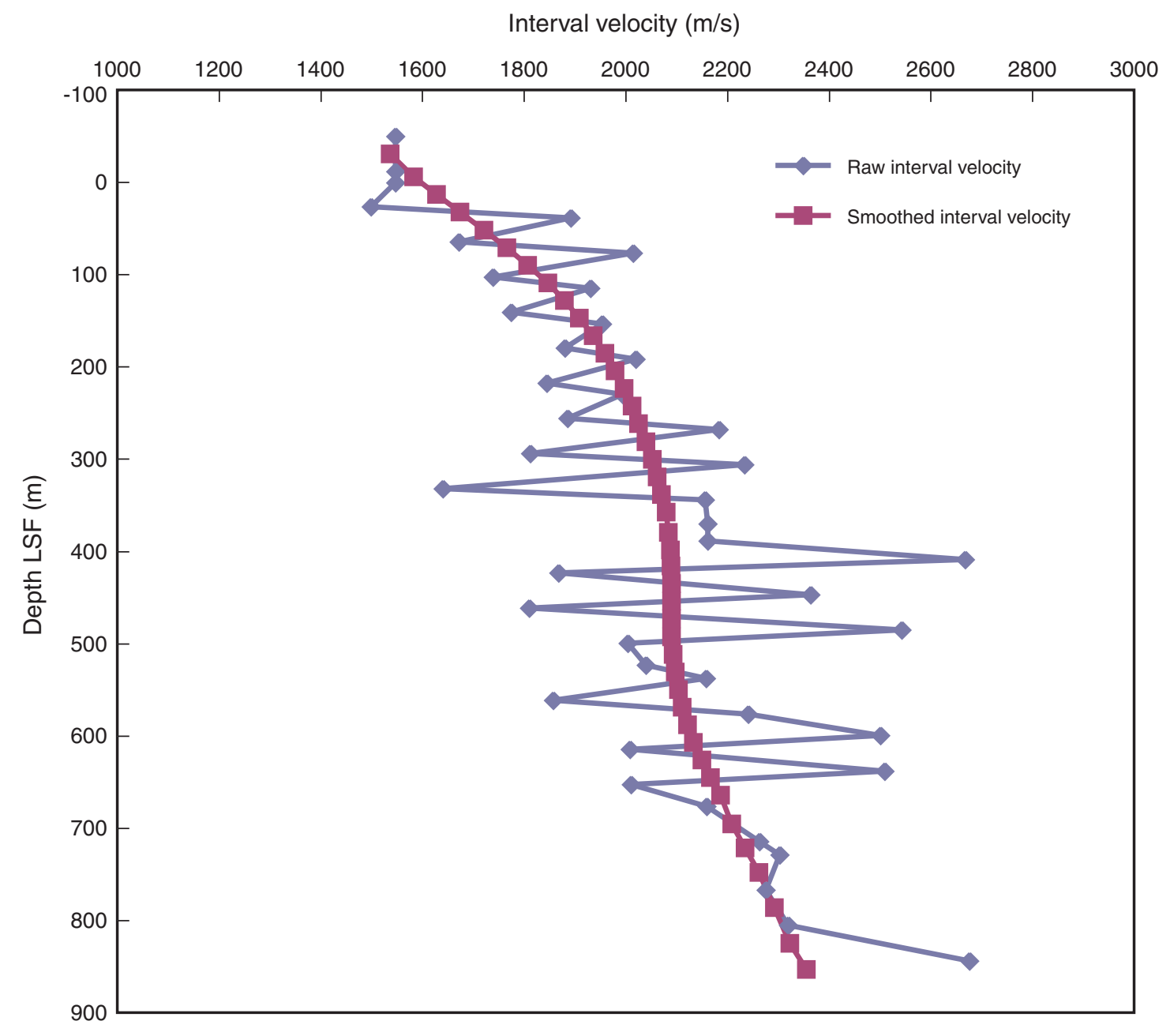


Figure F30. Logging units and subunits superimposed on check shot-corrected seismic profile. LSF $=$ LWD depth below seafloor. VE = vertical exaggeration.

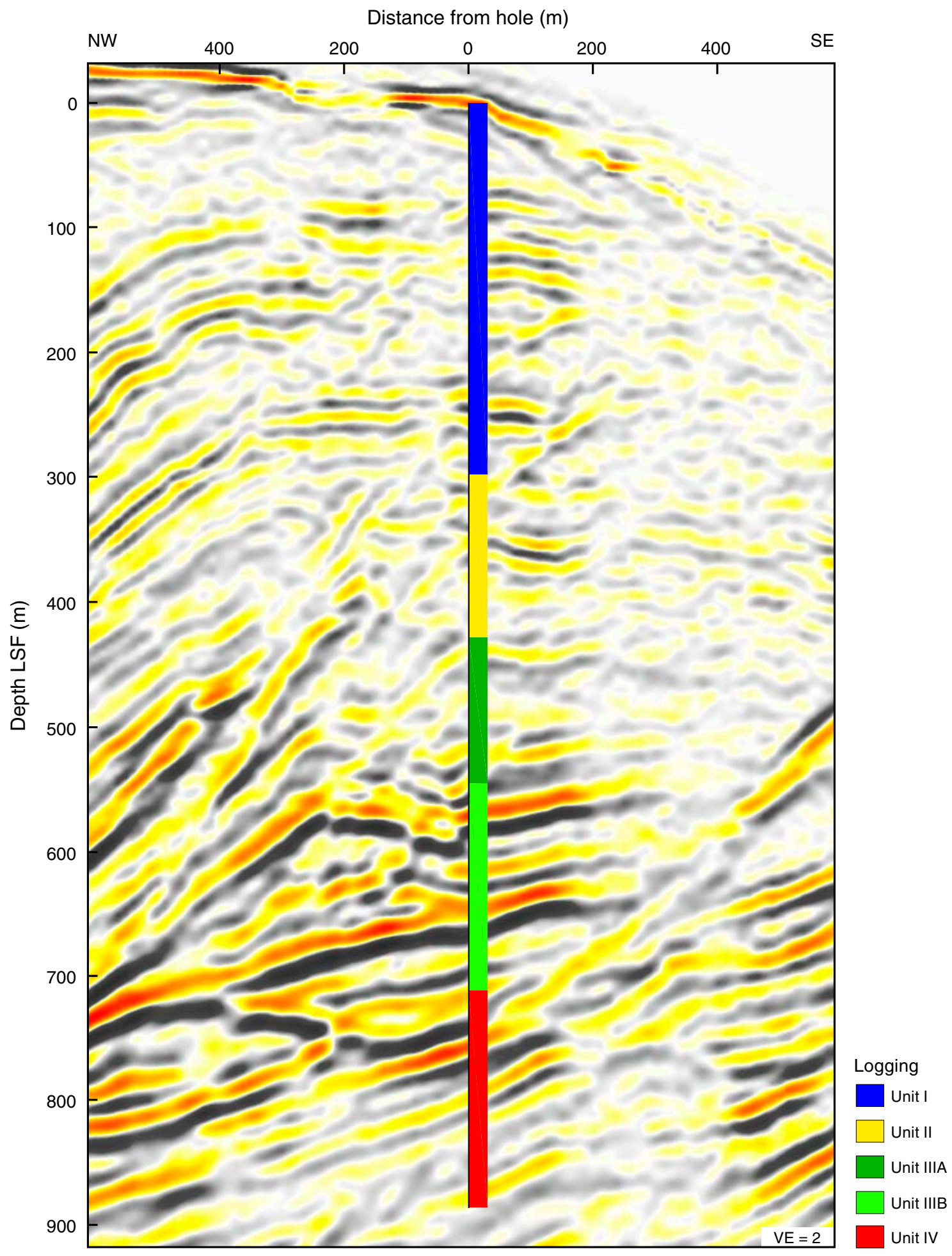


Figure F31. LWD gamma ray log superimposed on check shot-corrected seismic profile. LSF = LWD depth below seafloor. $\mathrm{VE}$ = vertical exaggeration.

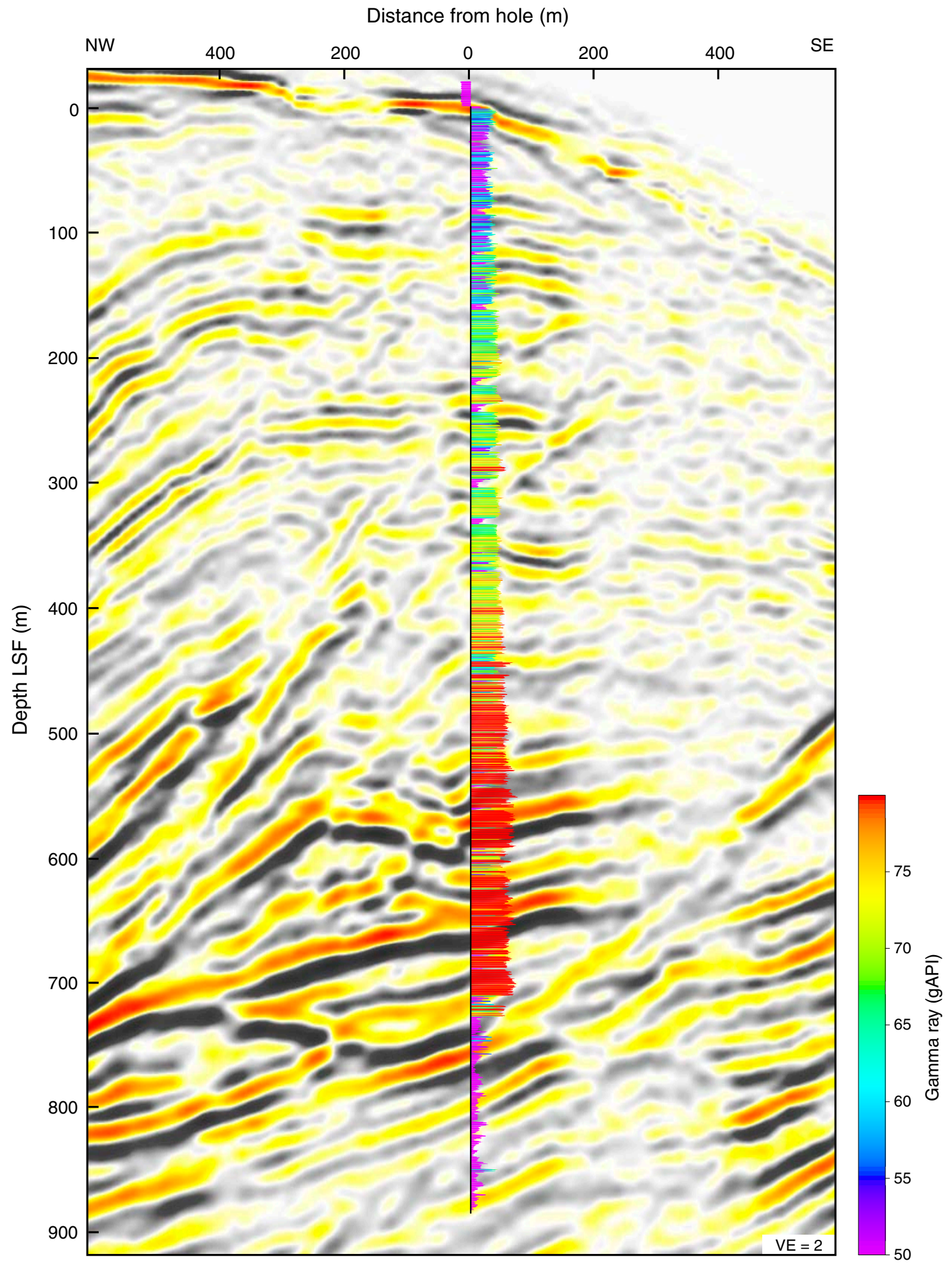


Figure F32. LWD bit resistivity superimposed on check shot-corrected seismic profile. LSF $=$ LWD depth below seafloor. $\mathrm{VE}$ = vertical exaggeration.

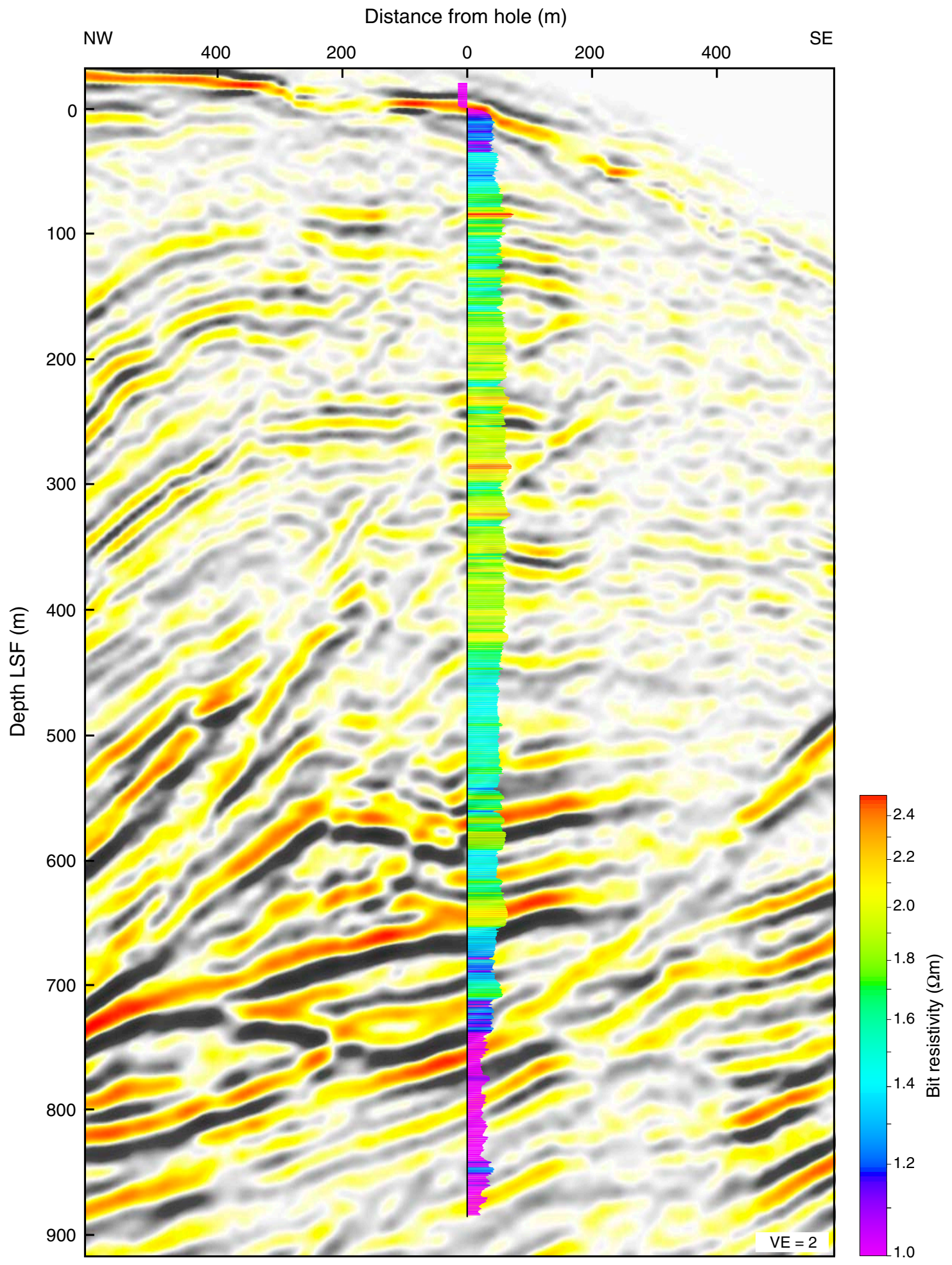


Figure F33. LWD ring resistivity superimposed on check shot-corrected seismic profile. LSF = LWD depth below seafloor. $\mathrm{VE}$ = vertical exaggeration.

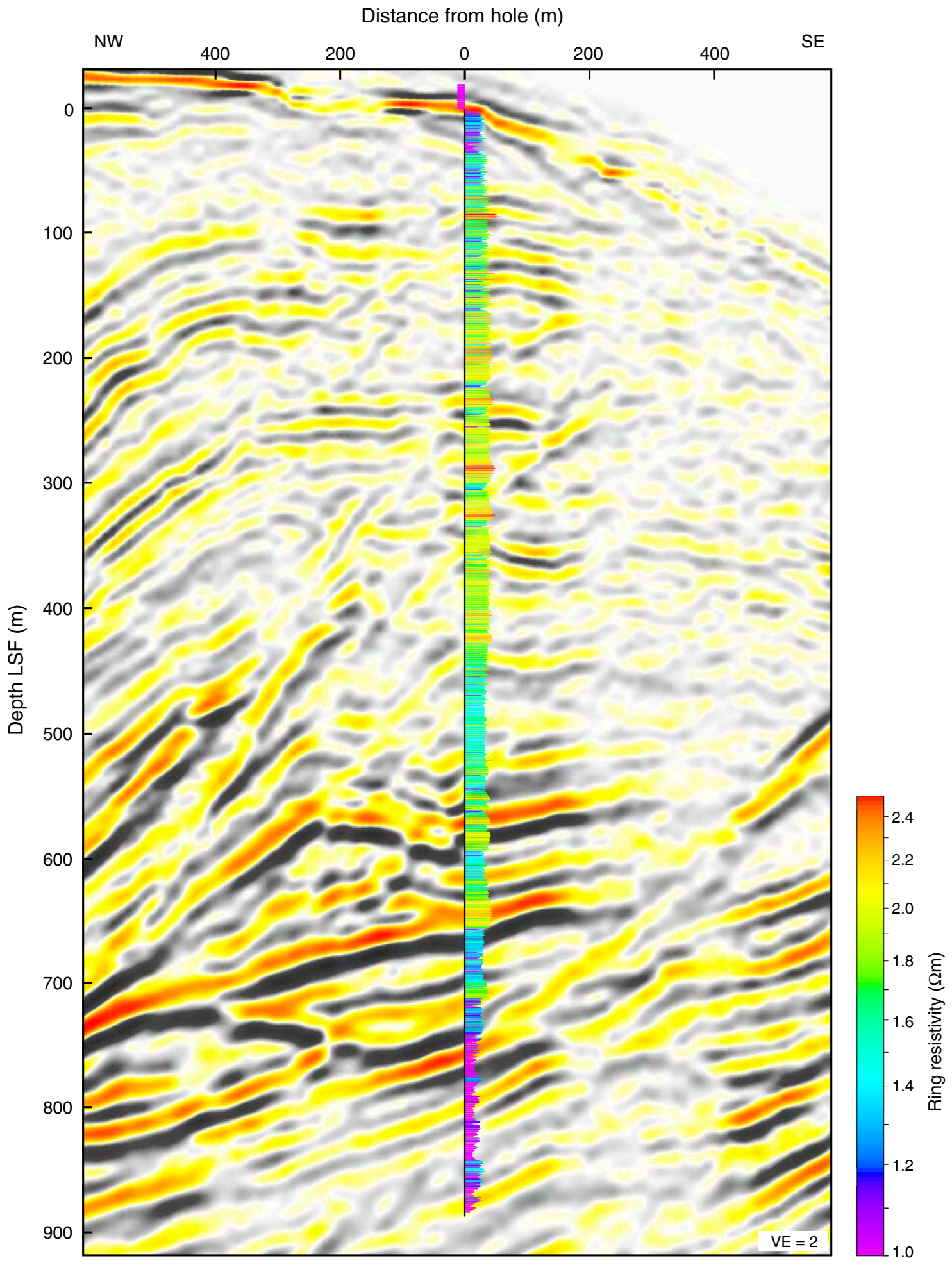


Figure F34. LWD caliper values superimposed on check shot-corrected seismic profile. LSF = LWD depth below seafloor. $\mathrm{VE}$ = vertical exaggeration.

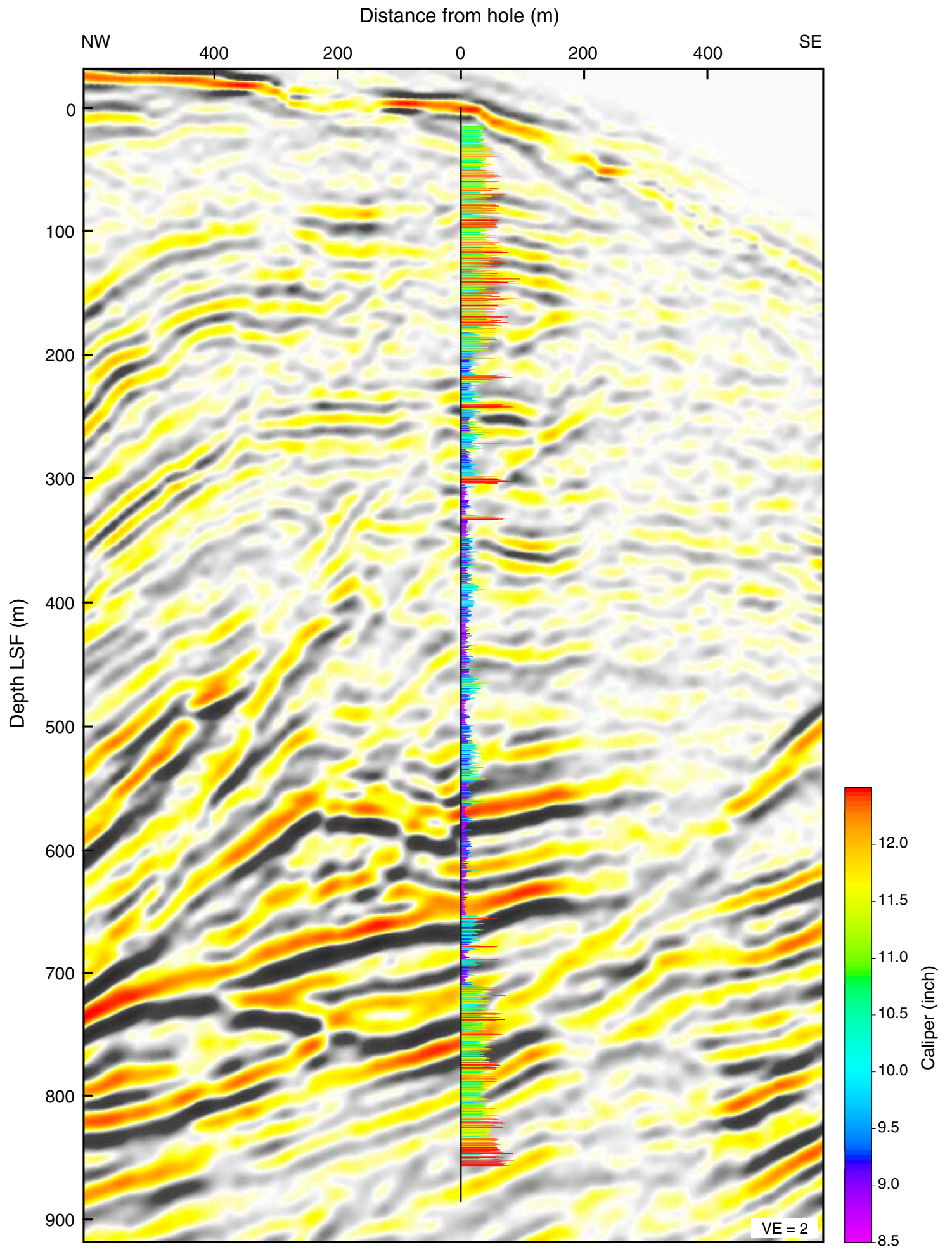


Table T1. Operations summary, Site C0006. (See table notes.)

\begin{tabular}{|c|c|c|c|c|c|c|}
\hline \multicolumn{5}{|c|}{$\begin{array}{l}\text { Hole C0006A } \\
\text { Latitude: } 33^{\circ} 01.6430^{\prime} \mathrm{N} \\
\text { Longitude: } 136^{\circ} 47.6550^{\prime} \mathrm{E} \\
\text { Seafloor (drill pipe measurement from rig floor, m): } 3903.5 \\
\text { Distance between rig floor and sea level }(\mathrm{m}): 28.5 \\
\text { Water depth (drill pipe measurement from sea level, } \mathrm{m} \text { ): } 3875\end{array}$} & & \\
\hline \multicolumn{7}{|c|}{$\begin{array}{l}\text { Hole C0006B } \\
\text { Latitude: } 33^{\circ} 01.6350^{\prime} \mathrm{N} \\
\text { Longitude: } 136^{\circ} 47.6390^{\prime} \mathrm{E} \\
\text { Seafloor (drill pipe measurement from rig floor, m): } 3900 \\
\text { Distance between rig floor and sea level (m): } 28.5 \\
\text { Water depth (drill pipe measurement from sea level, m): } 3871.5\end{array}$} \\
\hline \multirow[b]{2}{*}{ Operation } & \multicolumn{2}{|c|}{ Start } & \multicolumn{2}{|c|}{$\begin{array}{c}\text { Depth } \\
\text { (m LSF) }\end{array}$} & \multirow[b]{2}{*}{$\begin{array}{l}\text { Drilled } \\
\text { (m LSF) }\end{array}$} & \multirow[b]{2}{*}{ Comments } \\
\hline & $\begin{array}{l}\text { Date } \\
(2007)\end{array}$ & $\begin{array}{l}\text { Local } \\
\text { time (h) }\end{array}$ & & $\frac{\text { LSF) }}{\text { Bottom }}$ & & \\
\hline $\begin{array}{l}\text { Hole C0006A pilot hole } \\
\text { ROV survey } \\
\text { Spud-in } \\
\text { Ream and sweep } \\
\text { Ream and sweep } \\
\text { Reach total depth } \\
\text { Pull tools out of hole }\end{array}$ & $\begin{array}{l}8 \text { Nov } \\
10 \text { Nov } \\
10 \text { Nov } \\
11 \text { Nov } \\
11 \text { Nov } \\
11 \text { Nov }\end{array}$ & $\begin{array}{l}0415 \\
0015 \\
1415 \\
0500 \\
1045 \\
2045\end{array}$ & 0 & 885.5 & 885.5 & $\begin{array}{l}\text { 8-1/2 inch pilot hole with MWD-GR-APWD } \\
\text { Deploy } 5 \text { beacons with ROV } \\
\text { Jet-in to } 50.5 \mathrm{~m} \text { LSF; rotary drilling continued to TD } \\
\text { Short trip from } 4210 \text { to } 4060 \mathrm{~m} \text { DRF } \\
\text { Short trip from } 4504 \text { to } 4358 \mathrm{~m} \text { DRF } \\
\text { Pump sweep and spot kill mud } \\
\text { Check and tighten rig floor instruments while pulling out }\end{array}$ \\
\hline $\begin{array}{l}\text { Hole C0006B LWD hole } \\
\text { ROV survey } \\
\text { Spud-in } \\
\text { Rig floor maintenance } \\
\text { Ream and sweep } \\
\text { Reach total depth } \\
\text { Pull tools out of hole } \\
\text { Recover tools on the rig floor } \\
\text { Recover data }\end{array}$ & $\begin{array}{l}13 \mathrm{Nov} \\
13 \mathrm{Nov} \\
13 \mathrm{Nov} \\
14 \mathrm{Nov} \\
14 \mathrm{Nov} \\
14 \mathrm{Nov} \\
15 \mathrm{Nov} \\
15 \mathrm{Nov}\end{array}$ & $\begin{array}{l}0045 \\
0045 \\
1400 \\
0315 \\
1645 \\
1900 \\
1715 \\
1900\end{array}$ & 0 & 885.5 & 885.5 & $\begin{array}{l}\text { 8-1/2 inch LWD (GVR-sonic-SVWD-MWD-APWD) } \\
\text { Jet-in to } 40 \mathrm{~m} \text { LSF and rotary drill to TD } \\
\text { No real-time data, lost communication from MWD tool } \\
\text { Wiper trip between } 4502 \text { and } 4350 \mathrm{~m} \text { DRF } \\
\text { Pump sweep and spot kill mud } \\
\text { Pump and backream because of hole sticky condition }\end{array}$ \\
\hline
\end{tabular}

Notes: $L S F=L W D$ depth below seafloor. $R O V=$ remotely operated vehicle. $M W D=$ measurement while drilling, GR $=$ gamma ray, $A P W D=$ annular pressure while drilling. TD = total depth. DRF = drillers depth below rig floor. LWD = logging while drilling, GVR $=$ geoVISION resistivity tool, sonic = sonic while drilling (sonicVISION), SVWD = seismic VISION while drilling, MWD = measurement while drilling .

Table T2. Bottom-hole assembly, Hole C0006A. (See table notes.)

\begin{tabular}{lrr}
\hline \multicolumn{1}{c}{ BHA component } & $\begin{array}{c}\text { Length } \\
(\mathrm{m})\end{array}$ & $\begin{array}{c}\text { Cumulative } \\
\text { length } \\
\text { from bit } \\
(\mathrm{m})\end{array}$ \\
\hline PDC bit & 0.350 & 0.350 \\
Stabilizer/float sub & 0.610 & 0.960 \\
Crossover sub & 0.610 & 1.570 \\
Power pulse & 8.496 & 10.066 \\
Crossover sub & 0.480 & 10.546 \\
Crossover sub & 0.610 & 11.156 \\
Crossover sub & 0.610 & 11.766 \\
6-3/4 inch drilling collar & 9.310 & 21.076 \\
Stabilizer & 1.504 & 22.580 \\
6-3/4 inch drilling collar & 9.313 & 31.893 \\
6-3/4 inch drilling collar & 9.310 & 41.203 \\
6-3/4 inch drilling collar & 9.292 & 50.495 \\
6-3/4 inch drilling collar & 9.312 & 59.807 \\
6-3/4 inch drilling collar & 9.314 & 69.121 \\
6-3/4 inch drilling collar & 9.310 & 78.431 \\
6-3/4 inch drilling collar & 9.316 & 87.747 \\
Jar & 10.215 & 97.962 \\
6-3/4 inch drilling collar & 9.314 & 107.276 \\
Crossover sub & 0.611 & 107.887 \\
Crossover sub & 0.605 & 108.492 \\
\hline
\end{tabular}

Notes: $\mathrm{BHA}=$ bottom-hole assembly. $\mathrm{PDC}=$ polycrystalline diamond compact. 
Table T3. Bottom-hole assembly, Hole C0006B. (See table notes.)

\begin{tabular}{lrr}
\hline \multicolumn{1}{c}{ BHA component } & $\begin{array}{c}\text { Length } \\
(\mathrm{m})\end{array}$ & $\begin{array}{c}\text { Cumulative } \\
\text { length } \\
\text { from bit } \\
(\mathrm{m})\end{array}$ \\
\hline PDC bit & 0.350 & 0.350 \\
Stabilizer/float sub & 0.610 & 0.960 \\
Crossover sub & 0.615 & 1.575 \\
geoVISION & 3.084 & 4.659 \\
sonicVISION & 7.624 & 12.283 \\
Power pulse & 8.496 & 20.779 \\
seismicVISION & 4.640 & 25.419 \\
adnVISION & 6.098 & 31.517 \\
Crossover sub & 0.610 & 32.127 \\
6-3/4 inch drilling collar & 9.310 & 41.437 \\
6-3/4 inch drilling collar & 9.313 & 50.750 \\
6-3/4 inch drilling collar & 9.310 & 60.060 \\
6-3/4 inch drilling collar & 9.292 & 69.352 \\
6-3/4 inch drilling collar & 9.312 & 78.664 \\
6-3/4 inch drilling collar & 9.314 & 87.978 \\
6-3/4 inch drilling collar & 9.310 & 97.288 \\
6-3/4 inch drilling collar & 9.316 & 106.604 \\
Jar & 10.215 & 116.819 \\
6-3/4 inch drilling collar & 9.310 & 126.129 \\
Crossover sub & 0.611 & 126.740 \\
Crossover sub & 0.605 & 127.345 \\
\hline
\end{tabular}

Notes: $\mathrm{BHA}=$ bottom-hole assembly. $\mathrm{PDC}=$ polycrystalline diamond compact.

Table T4. Quality control characteristics and sonic log data, Hole C0006B. (See table notes.)

\begin{tabular}{rrcccl}
\hline $\begin{array}{c}\text { Depth interval } \\
(\mathrm{m} \text { LSF })\end{array}$ & & & \\
\cline { 1 - 2 } Top & Bottom & Zone & Quality & & \multicolumn{1}{c}{ Comments } \\
\hline 0 & 36 & 1 & 0 & Formation arrival cannot be distinguished from the mud arrival \\
36 & 160 & 1 & 1 & Fairly intermittent arrivals with zones of clear arrivals and zones hard to pick up on MP wide \\
\hline
\end{tabular}

Notes: LSF = LWD depth below seafloor. MP = mixed processing (see "Data and log quality").

Table T5. Quality control characteristics and resistivity image data, Hole C0006B. (See table note.)

\begin{tabular}{|c|c|c|}
\hline \multicolumn{2}{|c|}{$\begin{array}{l}\text { Depth interval } \\
\quad(\mathrm{m} \text { LSF })\end{array}$} & \multirow[b]{2}{*}{ Comments } \\
\hline Top & Bottom & \\
\hline 40 & 69 & $\begin{array}{l}\text { Resistivity variation on } 180^{\circ} \text { frequency, probably due to hole } \\
\text { enlargement and eccentricity of tool relative to borehole wall. }\end{array}$ \\
\hline 420 & 445 & Meter-scale spiral banding, suspected tool artifact. \\
\hline 480 & 520 & Meter-scale spiral banding, suspected tool artifact. \\
\hline 520 & 595 & Meter-scale spiral banding, suspected tool artifact. \\
\hline 619 & 633 & Meter-scale spiral banding, suspected tool artifact. \\
\hline 733 & 819 & $\begin{array}{l}\text { Resistivity variation on } 180^{\circ} \text { frequency, probably due to hole } \\
\text { enlargement and eccentricity of tool relative to borehole wall. }\end{array}$ \\
\hline 40 & 885 & $\begin{array}{l}\text { Centimeter-scale horizontal banding, suspected tool artifact, } \\
\text { tends to obscure shallowly dipping bedding and fractures. }\end{array}$ \\
\hline
\end{tabular}

Note: LSF = LWD depth below seafloor. 
Table T6. Logging units defined by LWD data. (See table note.)

\begin{tabular}{|c|c|c|c|c|}
\hline \multicolumn{2}{|c|}{ Logging } & \multirow{2}{*}{$\begin{array}{l}\text { Depth } \\
\text { (m LSF) }\end{array}$} & \multirow[b]{2}{*}{ Description } & \multirow[b]{2}{*}{ Lithologic interpretation } \\
\hline Unit & Subunit & & & \\
\hline 1 & & $0-197.8$ & $\begin{array}{l}\text { Gamma ray increasing trend, high-frequency and high-amplitude fluctuation of gamma ray } \\
\text { values. Gradual increasing trend of resistivity. Strong fluctuation of resistivity. }\end{array}$ & Sandy and muddy sediments \\
\hline II & & $197.8-428.3$ & $\begin{array}{l}\text { Gradual increasing trend of gamma ray baseline. Occasional thick }(5 \mathrm{~m}) \text { low gamma ray layers. } \\
\text { Constant resistivity baseline with frequent thick conductive zones. }\end{array}$ & Mudstone with thick sand \\
\hline \multirow[t]{2}{*}{ III } & A & $428.3-545.3$ & $\begin{array}{l}\text { High gamma ray baseline with thin }(1 \mathrm{~m} \text { ) low gamma ray layers. Less variable and slight } \\
\text { decreasing trend of resistivity. }\end{array}$ & $\begin{array}{l}\text { Alternating beds of mudstone } \\
\text { and sand (mud dominant) }\end{array}$ \\
\hline & B & $545.3-711.5$ & $\begin{array}{l}\text { High gamma ray baseline with large number of thin }(1 \mathrm{~m}) \text { low gamma ray layers. General } \\
\text { decreasing and variable (repeated increasing) trend of resistivity. }\end{array}$ & $\begin{array}{l}\text { Alternating beds of mudstone } \\
\text { and sand (sand dominant) }\end{array}$ \\
\hline IV & & 711.5-TD & Low gamma ray and low resistivity. & Sand \\
\hline
\end{tabular}

Note: $L S F=$ LWD depth below seafloor. TD = total depth.

Table T7. Logging unit boundaries defined by LWD data. (See table note.)

\begin{tabular}{|c|c|c|c|}
\hline $\begin{array}{l}\text { Depth } \\
\text { (m LSF) }\end{array}$ & \multicolumn{2}{|c|}{ Unit boundary } & Description \\
\hline 79.8 & Minor & & Low-amplitude to high-amplitude fluctuation of gamma ray. End of increasing trend of resistivity. \\
\hline 146.1 & Minor & & High-amplitude to low-amplitude fluctuation of gamma ray. \\
\hline 197.8 & Medium & $1 / 11$ & High-frequency and high-amplitude to low-frequency and low-amplitude fluctuation of resistivity. \\
\hline 293.0 & Minor & & Baseline shift of resistivity. \\
\hline 428.3 & Medium & II/III & Baseline shift of resistivity. \\
\hline 545.3 & Medium & IIIA/IIIB & High-frequency to low-frequency fluctuation of gamma ray. Constant to variable values of resistivity. \\
\hline 593.4 & Medium & & Baseline shift of gamma ray, resistivity, and caliper. \\
\hline 657.0 & Medium & & Baseline shift of resistivity and caliper. \\
\hline 711.5 & Major & III/IV & Strong baseline shift of gamma ray. Baseline shift of resistivity and caliper. \\
\hline 764.4 & Medium & & High-frequency to low-frequency fluctuation of resistivity. \\
\hline
\end{tabular}

Note: LSF = LWD depth below seafloor. 
Table T8. Check shot raw and smoothed traveltimes and calculated interval velocities, Site C0006. (See table notes.)

\begin{tabular}{|c|c|c|c|c|c|}
\hline \multirow[b]{2}{*}{$\begin{array}{l}\text { Depth* } \\
\text { (m LSF) }\end{array}$} & \multirow[b]{2}{*}{$\begin{array}{c}\text { Midpoint } \\
\text { depth }^{\dagger} \\
(\mathrm{m} \text { LSF) }\end{array}$} & \multicolumn{2}{|c|}{ Raw } & \multicolumn{2}{|c|}{ Smoothed } \\
\hline & & $\begin{array}{l}\text { First arrival } \\
\text { time* } \\
(\mathrm{ms})\end{array}$ & $\begin{array}{c}\text { Interval } \\
\text { velocity }{ }^{\dagger} \\
(\mathrm{m} / \mathrm{s})\end{array}$ & $\begin{array}{l}\text { First arrival } \\
\text { time* } \\
(\mathrm{ms})\end{array}$ & $\begin{array}{c}\text { Interval } \\
\text { velocity } \\
(\mathrm{m} / \mathrm{s})\end{array}$ \\
\hline-49.98 & -30.86 & 2556.8 & 1547 & 2556.9 & 1537 \\
\hline-11.75 & -5.65 & 2581.5 & 1547 & 2581.8 & 1582 \\
\hline 0.45 & 13.46 & 2589.4 & 1548 & 2589.5 & 1628 \\
\hline 26.47 & 32.57 & 2606.2 & 1499 & 2605.5 & 1674 \\
\hline 38.68 & 51.69 & 2614.3 & 1892 & 2612.8 & 1721 \\
\hline 64.70 & 70.80 & 2628.1 & 1672 & 2627.9 & 1766 \\
\hline 76.90 & 89.91 & 2635.4 & 2015 & 2634.8 & 1807 \\
\hline 102.92 & 109.02 & 2648.3 & 1739 & 2649.2 & 1847 \\
\hline 115.12 & 128.13 & 2655.3 & 1931 & 2655.8 & 1880 \\
\hline 141.14 & 147.24 & 2668.8 & 1775 & 2669.6 & 1909 \\
\hline 153.35 & 166.37 & 2675.7 & 1954 & 2676.0 & 1936 \\
\hline 179.40 & 185.47 & 2689.0 & 1880 & 2689.5 & 1959 \\
\hline 191.54 & 204.58 & 2695.5 & 2020 & 2695.7 & 1979 \\
\hline 217.62 & 223.71 & 2708.4 & 1845 & 2708.9 & 1997 \\
\hline 229.79 & 242.80 & 2715.0 & 1993 & 2715.0 & 2012 \\
\hline 255.81 & 261.90 & 2728.0 & 1886 & 2727.9 & 2025 \\
\hline 267.99 & 281.01 & 2734.5 & 2184 & 2733.9 & 2040 \\
\hline 294.04 & 300.14 & 2746.4 & 1812 & 2746.7 & 2052 \\
\hline 306.24 & 319.25 & 2753.1 & 2233 & 2752.6 & 2062 \\
\hline 332.26 & 338.36 & 2764.8 & 1641 & 2765.2 & 2070 \\
\hline 344.47 & 357.48 & 2772.2 & 2156 & 2771.1 & 2079 \\
\hline 370.48 & 379.61 & 2784.3 & 2162 & 2783.6 & 2084 \\
\hline 388.73 & 398.72 & 2792.7 & 2161 & 2792.4 & 2088 \\
\hline 408.71 & 416.01 & 2802.0 & 2668 & 2802.0 & 2090 \\
\hline 423.31 & 435.10 & 2807.5 & 1868 & 2809.0 & 2090 \\
\hline 446.90 & 454.20 & 2820.1 & 2364 & 2820.2 & 2090 \\
\hline 461.50 & 473.31 & 2826.3 & 1810 & 2827.2 & 2090 \\
\hline 485.12 & 492.44 & 2839.3 & 2543 & 2838.5 & 2090 \\
\hline 499.76 & 511.57 & 2845.1 & 2004 & 2845.5 & 2093 \\
\hline 523.38 & 530.68 & 2856.9 & 2040 & 2856.8 & 2097 \\
\hline 537.98 & 549.79 & 2864.0 & 2158 & 2863.8 & 2103 \\
\hline 561.60 & 568.90 & 2875.0 & 1858 & 2875.0 & 2112 \\
\hline 576.20 & 588.00 & 2882.8 & 2241 & 2881.9 & 2122 \\
\hline 599.79 & 607.11 & 2893.3 & 2501 & 2893.0 & 2134 \\
\hline 614.43 & 626.22 & 2899.2 & 2008 & 2899.9 & 2150 \\
\hline 638.02 & 645.32 & 2910.9 & 2509 & 2910.9 & 2167 \\
\hline 652.62 & 664.43 & 2916.8 & 2011 & 2917.6 & 2187 \\
\hline 676.24 & 695.32 & 2928.5 & 2159 & 2928.4 & 2209 \\
\hline 714.40 & 721.71 & 2946.2 & 2263 & 2945.7 & 2235 \\
\hline 729.03 & 748.14 & 2952.7 & 2303 & 2952.2 & 2262 \\
\hline 767.26 & 786.38 & 2969.2 & 2276 & 2969.1 & 2292 \\
\hline 805.51 & 824.64 & 2986.1 & 2320 & 2985.8 & 2322 \\
\hline 843.77 & 853.43 & 3002.6 & 2677 & 3002.3 & 2355 \\
\hline 863.09 & - & 3009.8 & - & 3010.5 & - \\
\hline
\end{tabular}

Notes: Smoothed values were used in the generation of synthetic seismograms and time-depth conversion of seismic reflection profiles near the site. ${ }^{*}=$ first arrival time picks associated with depths of observations, $\dagger=$ interval velocities associated with midpoints between depths of observations. LSF $=$ LWD depth below seafloor. $-=$ no data. 